\title{
A High-Power Multiphase Wireless Dynamic Charging System with low Output Power Pulsation for Electric Vehicles
}

\author{
Van-Binh Vu, Student Member, Mohamed Dahidah, Senior Member, IEEE, Volker Pickert, Member, IEEE and \\ Van-Tung Phan, Senior Member, IEEE.
}

\begin{abstract}
Wireless Dynamic Charging (WDC) of Electric Vehicles (EV) is a new initiative aimed to increase EV uptake. However, pulsating output power along the driving direction is a major problem with this technology. Moreover, in order to deliver enough driving power for EVs, WDC systems must operate at high power. This paper proposes a WDC system that has the capability of providing a low pulsating and high output power to EVs. The proposed WDC utilizes multiple primary windings that guarantees a homogeneous mutual magnetic flux for the receiver along the driving direction. This results in a constant induced voltage across the receiver and hence constant output power to charge the EV battery. High output power is realized by using multiple transmitter windings which have been arranged in a novel winding method. The structure layout of the proposed WDC, including ferrite cores, windings and resonant tanks is presented. Furthermore, a theoretical analysis is conducted to determine conditions of each winding's current phase and amplitude for achieving constant output power. The crossing mutual inductances between the different transmitter's phases are compensated by adding small capacitors in series with each transmitter winding. An optimization analysis using Maxwell 3D simulation for both, transmitter and receiver is carried out to achieve the highest coupling factor by using minimum ferrite material. The effectiveness of the proposed system is analytically demonstrated and experimentally verified using a 3-kW laboratory prototype. Finally, the performance of the proposed method is compared with similar systems presented in the literature. The comparison shows that the proposed system has the advantages of using simple control, it also eliminates communications between the primary and secondary side and delivers a normalized power of 2.25 which is $125 \%$ higher compared to conventional single-phase systems.
\end{abstract}

Index Terms - Dynamic Wireless Charging Inductive Power Transfer, Electric Vehicle Battery Charger, Constant Output Power.

\section{INTRODUCTION}

Electric vehicles (EV) have recently received a great deal of attention because of their clean, efficient and environmentfriendly features [1]. The high penetration of EVs still limited at present time due to many technological barriers, including battery capacity. An expensive and large battery with long charging time is normally equipped to achieve satisfactory $\mathrm{EV}$ driving range. To mitigate this problem, the concept of WDC has been proposed in [2] to overcome the limitation of current battery technology. WDC enables EV to be charged wirelessly while in motion. As a result, the battery size of EVs can be greatly reduced and the driving range limitation can be

Manuscript received April 17, 2019; revised June 03, 2019; accepted July 24, 2019 This work was funded by Newcastle University. (Corresponding author: Van-Binh Vu.).

The authors are with the School of Engineering, Merz Court, Newcastle University, Newcastle upon Tyne, NE1 7RU, U.K. (e-mail: V.B.Vu2@ncl.ac.uk; mohamed.dahidah@newcastle.ac.uk; volker.pickert@newcastle.ac.uk; vantung.phan @ newcastle.ac.uk).

Color versions of one or more of the figures in this paper are available online at http://ieeexplore.ieee.org completely alleviated. WDC is commonly developed based on inductive power transfer (IPT) technology, where a time varying magnetic field is generated by transmitter coils; which are installed underneath road surface, to wirelessly power receiver coils, which charging the EV's battery continuously [3]-[5].

A WDC are categorized into short-individual transmitters [6-8] or long-track transmitters [9-11] according to the length of transmitter coils (i.e. Fig. 1a and Fig. 1b respectively). In the short-individual transmitters, the transmitter dimension is the same as the receiver, which is typical within $1 \mathrm{~m}^{2}$. Furthermore, multi-transmitter coils are arranged in the primary side to alternatively transfer power to secondary side. Additionally, each transmitter is connected to an independent compensation circuit, which can be switched ON or OFF depending on the EV's position. When the EV's receiver is in align with a specific transmitter, then the power switch (or contactor) connects the associated inverter. In order to switch a specific transmitter, position sensors and associated electronic circuit are required. Therefore, the effect of the electromagnetic field to surrounding environment is minimized and total conduction losses on transmitters are reduced. Moreover, the high efficiency can be achieved due to high values of coupling coefficient between transmitter and receiver coil. However, the short-individual transmitters requires more inverters, position sensors and other control circuitries that make the system more complicated. More importantly, when the EV moves between two adjacent transmitters, the output power becomes pulsating and significantly reduced.

On the other hand, long-track transmitter [9-11] is much longer than the EV's length and only requires a single power inverter with one compensation tank. This brings benefits in terms of cost and simplicity for implementation of such a system. However, the low coupling coefficient is indicated as the main drawback of this system as the receiver coil covers only a small portion of the long transmitter coil Consequently, the efficiency is reduced and electromagnetic interference (EMI) is increased. Several studies are conducted to address EMI problem and also to simplify the structure of the system [12-14]. In [12] and [13], I-type and S-type transmitters are proposed with a width of $10 \mathrm{~cm}$ and 4 $\mathrm{cm}$, respectively. Additional, by adopting the alternating magnetic polarity for adjacent poles, the EMI around the transmitter coils can be substantially reduced through electromagnetic field cancelation between two adjacent magnetic poles of opposite polarity. The N-type is proposed in [14] to further reduce the volume of ferrite core while maintaining the advantages of I-type structure. However, the studies also pointed out that the magnetic flux density generated by I-type, S-type or N-type power supply on a single receiver varies in a nearly sinusoidal function depending on receiver's position along the driving direction. 
According to [12], magnetic flux density reaches to its maximum at the centre of each ferrite pole and reduces to nearly zero at the centre between two adjacent poles. As a consequence, the induced voltage and received power are significantly varied depending on EV's position. The received output power even reaches to nearly zero at some specific position of EV while moving along the transmitter.

As discussed in the above literature, the output power variation is one of the most serious problems for WDC, in both short-track and long-track systems. Therefore, a number of studies attempted to realize constant output power. For example, in short-track system, the stable output power is achieved by proper design of the compensation network to compensate for misalignment [15-16]. However, this can only be attained for a narrow range of misalignment. Further, in [17], the variation of the output power is reduced by arranging the transmitter segments closer to each other. However, this can be only achieved at a certain dimensions of the transmitter and receiver. In [18], the low output power variation is attained by adopting three half-bridge inverters connected in parallel as well as optimizing the receiver length. Constant power is only achieved if the ratio of receiver's length over transmitter's length is 1.5 , which may not be suitable in real practical applications where receivers with different dimensions are required. Other methods are proposed in [19-20] by adjusting the transmitter current under misalignment. Transmitter current is controlled by a primary inverter and/or a DC/DC converter to increase its amplitude when coupling between two sides is reduced. However, overall efficiency is decreased as the increase in losses on Inverter and Transmitter winding. Moreover, mutual inductance measurement and communication between two sides are required while $\mathrm{EV}$ is in motion.

Similarly, several attempts have been reported in the literature aiming at reducing the output pulsation of longtrack systems. For instance, authors in [21] added additional receiver windings to create a multiphase receiver system with a single primary transmitter. The coils dimensions in both sides are optimized to achieve constant power at the output side. Another solution was suggested by [22], where two primary transmitter coils with two independently controlled inverters are arranged. The constant output power can be attained by controlling the output amplitude and phase of the two inverters. However, this requires information from the secondary side such as load resistance and mutual inductances, which results in a complicated measurement and communication especially when the EV is in motion. Furthermore, the control method presented in [22] becomes even more complicated when multiple loads (EVs) are considered, simultaneously.

Besides output power pulsation problems, the transferred power of a single-phase WDC system is also limited by the rating of semiconductor devices, transmitter coil and compensation circuit. In real applications, several EVs may need to be charged simultaneously, thus the high power demand becomes a necessity. Moreover, the power level required for public transport such as electric bus or train systems may go up to hundreds of kilowatts or even megawatts scale [23]. In these applications, single-phase system may not be able to produce such a requirement. Therefore, multi-phase systems are seen as a solution to transfer higher output power [24-25].

The work in this paper achieves for the first time constant and high output power through the utilization of multiphase transmitter system. The transmitter system is constructed using multiple magnetic poles with different polarities and multiple windings. It should be noted that the proposed system possesses the same features of [12 -14], however it delivers higher and constant power. A multiphase inverter is adopted to produce the required currents (i.e. amplitude and phase) for each transmitter's winding. Modified primary LCC tank is proposed to compensate for the crossing coupling between transmitter windings. The paper presents a generalized multiphase system, however the number of phases is selected based on the required output power. Maxwell 3D simulations is carried out to design and optimize the magnetic components for attaining the highest value of coupling factor with a minimum ferrite core under misalignment conditions. The proposed concept is validated with an illustrative example based on a three-phase system. A scale down laboratory prototype of $3-\mathrm{kW}$ is developed to experimentally verify the feasibility and effectiveness of the proposed system. Furthermore, in order to show the superiority of the proposed system, a comparison with similar systems is carried out [12-14], [21-22]. The following are the main benefits:

(1) Achieving constant output power with a simple control requirement.

(2) Less number of inverters compared to [22].

(3) Elimination of measurement of mutual inductance and load impedance as well as communication between the grid and vehicle side while the EV is in motion.

(4) Attainting higher output power (i.e. 2.25 higher for the three-phase case) for the same system parameters, e.g. mutual inductance, transmitter's current, switching frequency and receiver's dimension, compared to the single-phase system.

(5) Unlike the previous systems, the proposed approach can be easily extended to multiple EV charging without any changes to the primary side control. This will be more suitable for real scenarios.

The paper is organized as follows. The proposed circuit configuration and multiphase transmitter layout are presented in Section II. An illustrative design example with three-phase system is mentioned in Section III. In Section IV, an optimized design of transmitter and receiver is conducted to achieve the highest of coupling factor. A $3-\mathrm{kW}$ prototype is built and tested to demonstrate the validity of the proposed method and to evaluate the performance of the proposed WDC system. The system comparison with other similar systems $[12,13,14,21,22]$ is presented in Section V. Finally, some conclusions are given in Section VI.

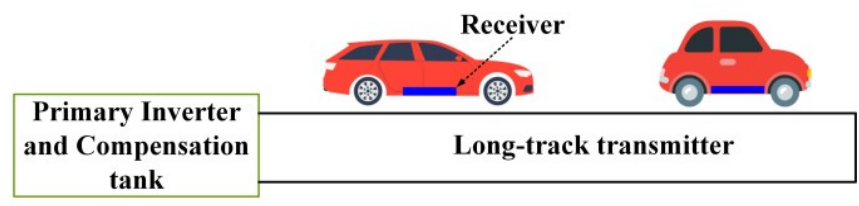

(a)

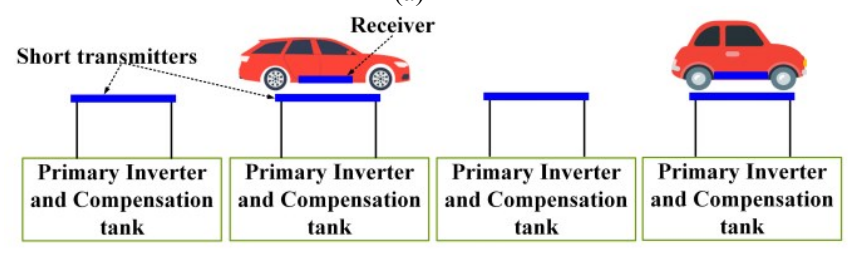

(b)

Fig. 1. Two types of WDC. (a) Long track transmitter; (b) Short-individual transmitters 


\section{Analysis of The Proposed Multiphase WDC}

\section{A. The circuit configuration}

Fig. 2a illustrates the proposed multiple transmitters WDC aiming to achieve constant output power for an EV's dynamic charging system. Primary side consists of $n$ transmitters $L_{i}(i=1,2, \ldots, n)$ energizing one receiver coil, $L_{s}$. As these transmitters are physically placed closed to each other, crossing couplings exists between them as depicted in Fig. 2.a The mutual inductances between transmitter $L_{i}$ and receiver is denoted by $M_{i s}(i=1,2, \ldots, n)$. In the experiment a $0.2-\Omega$ resistance was measured for each transmitter coil. At $3 \mathrm{~kW}$ output power an RMS current of $14 \mathrm{~A}$ is required and this produces a total loss of $120 \mathrm{~W}$. As such a small percentage is caused by the coils' resistances, then their values are neglected in the analysis for simplicity. Each transmitter is driven by a constant current source regardless of load and coupling coefficient conditions. Detailed structures of transmitter and receiver are described in the next Section. A multi-phase $\mathrm{DC} / \mathrm{AC}$ inverter is adopted at the primary side to produce a high frequency $\mathrm{AC}$ voltage for each transmitter. The Inverter consists of $n$ legs, namely leg 1 , leg $2, \ldots$, leg $i, \ldots$ leg $n$. Each leg has two switches that operate complementally to avoid short circuiting the dc supply. The operating waveforms of the multi-phase inverter is depicted in Fig. 2b, which includes the gate signals of active switches and the associated inverter's output voltages. The phase-shift between two adjacent legs' output voltages (i.e. $V_{(i-1) i}$ and $\left.V_{i(i+1)}\right)$ is set at $2 \pi / n$. The switching frequency of the inverter is chosen to be $85 \mathrm{kHz}$, in accordance with SAE J2954 standard [26] and the period of gate signal is $T=1 / f$.

A modified LCC resonant circuit based on [27], which consists of $L_{i a}, C_{i a}$ and $C_{i b}(i=1,2, \ldots, n)$, is used in primary side. In order to produce constant transmitter currents $I_{i}(i=1,2, \ldots, n)$, the resonance between $L_{i a}$ and $C_{i a}$ is set at the switching frequency of the inverter. The series capacitors $C_{i b}(i=1,2, \ldots, n)$ are used here for two purposes: (1) to resonate with the transmitter's inductance $L_{i}$ and (2) to suppress the induced voltages caused by the cross-couplings from other transmitters. Therefore, values of $C_{i b}(i=$ $1,2, \ldots, n)$ in this work are different from previous papers on LCC resonant network [4], [27]. Please note that the phase of the transmitter current $I_{i}$ is always leading 90 degrees as compared to the phase of Inverter's output voltage $V_{i(i+1)}$. At the secondary side, another LCC resonant tank is connected with a full-bridge rectifier to provide DC power to the output load. There should be another DC/DC regulator after the rectifier for battery charging purposes. However, for simplicity, only resistive load is used to investigate the proposed method. The proposed layout of primary transmitters and conditions of currents $I_{i}(i=1,2, \ldots, n)$ are further detailed in the following subsections. It is worth noting that the configuration in Fig. 2(a) is only applicable with a minimum number of phases $(n)$ of three. However, when $n$ equals to 1 or 2 , the primary inverter connection needs to be modified as shown in Fig. 2(c) and (d).

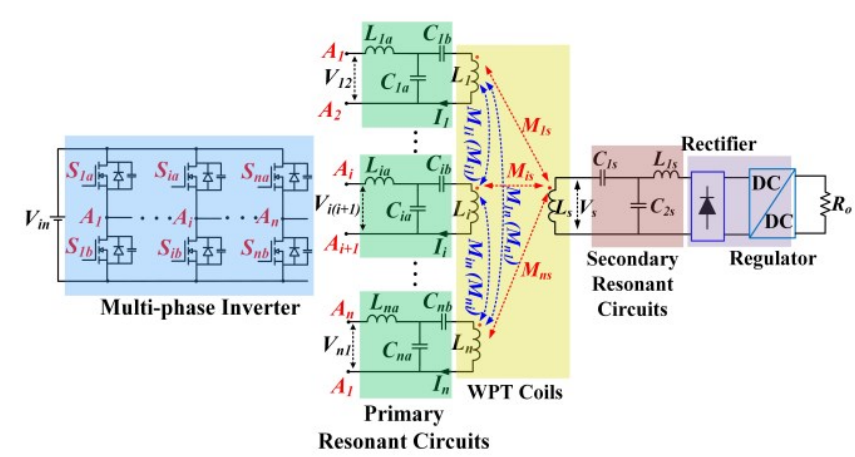

(a)

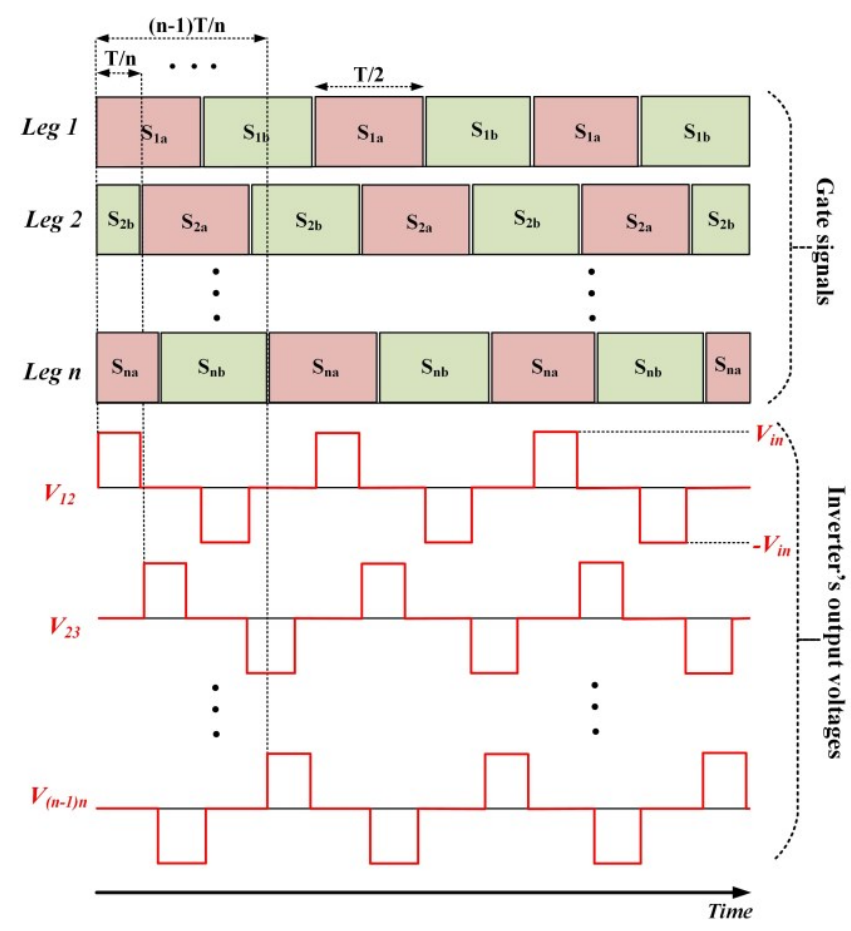

(b)
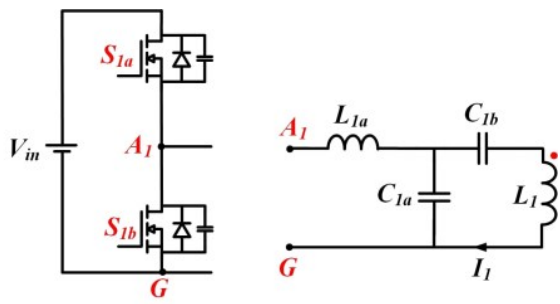

(c)
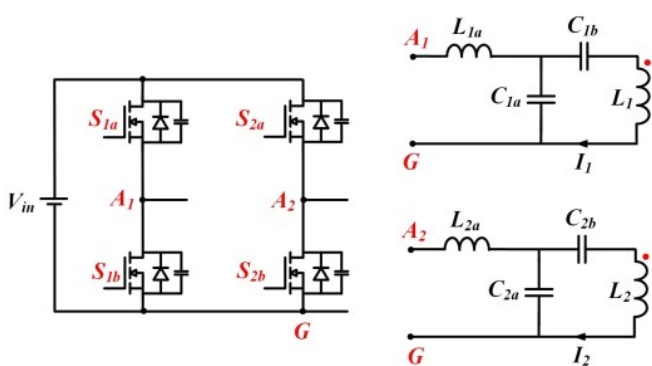

(d)

Fig. 2 (a) The proposed WDC circuit with multiple transmitter coils $(n \geq 3)$, (b) The operating waveforms of the multiphase Inverter, Modification of inverter connection with (c) $n=1$, (d) $n=2$

B. The layout of the proposed multiple transmitters 
The derivation of the proposed system is inspired by the limitations of a single transmitter system. Fig. 3(a) illustrates WDC that consists of multiple alternating magnetic I-pole core, where the receiver is covering one magnetic pole. When receiver is perfectly aligned with center of each magnetic pole, i.e. completely covers the winding loop, then mutual inductance will reach its maximum value. On the other hand, the mutual inductance drops to zero when the receiver centers at the middle point between each adjacent poles, where the magnetic fluxes cancel each other (i.e. same magnitude but opposite directions), resulting in no induced voltage. Therefore, as the receiver (EV) moves along the transmitter, spatial periodic induced voltage and power $\left(P_{o}\right)$ are obtained, which both are proportional with mutual inductance value. Consequently, as the vehicle travels along, the battery will not receive any power at the points of zero-mutual-inductance (i.e. pulsating power). The spatial distribution of mutual inductance between a single transmitter and receiver $M_{1 s}(x)$ can be approximately expressed by Eq. (1) where $M_{o}$ and $l_{o}$ are the maximum mutual inductance and the length of two adjacent poles respectively. The measured and simulated mutual inductance for $2.4 \mathrm{~m}$ and 4-pole single transmitter system are portrayed in Fig 3(b) (detailed parameters can be found in Section IV).

$$
M_{1 s}(x)=M_{o} \sin \left(\frac{2 \pi x}{l_{o}}\right)
$$

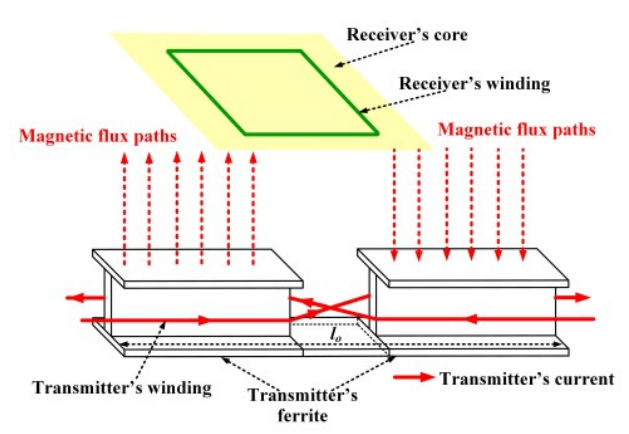

(a)

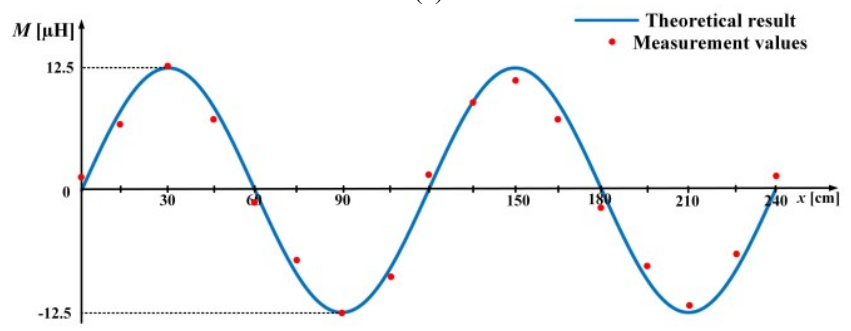

(b)

Fig. 3 Single transmitter system (a) Side view when receiver positions in lowest mutual inductance point (b) Spatial distribution of mutual inductances In order to solve abovementioned problems, additional transmitters can be added into the original system to nullify the zero mutual inductance points. The number of additional transmitters is determined by the output power requirement volt-ampere capability of the system components such as power switches, transmitter coils and resonant capacitors. However, increasing number of transmitters results in higher implementing costs, therefore the selection of number of transmitter is a trade-off between cost and reliability. To attain a constant output power, it is essential to ensure that all mutual inductances $M_{i s}(x)(i=2,3, \ldots, n)$ are evenly distributed along the transmitter length to avoid any zero mutual inductance points. It refers that between any two adjacent null points of $M_{1 s}(x)$, there are new $(n-1)$ null points from added $M_{i s}(x)(i=2,3, \ldots, n)$. In other words, the phase difference between any two adjacent mutual inductances $M_{i s}(x)$ and $M_{(i+1) s}(x)$ should be equal as illustrated in Fig. 4. It is also avoided to add new null points of all additional $M_{i s}(x)(i=2,3, \ldots, n)$ into the same positions with the existing one of $M_{1 s}(x)$, otherwise, added $M_{i s}(x)$ does not contribute to compensate the null-point of $M_{1 s}(x)$. The phase-shift difference between any two adjacent mutual inductance curves $M_{i s}(x)$ and $M_{(i+1) s}(x)$ is set at $2 \pi / n$. Equation (2) expresses all $(n)$ mutual inductances (i.e. $\left.M_{i s}(x)(i=1,2, \ldots, n)\right)$ including the original $M_{1 s}(x)$. It is worth mentioning that $M_{(i+1) s}(x)$ can be either leading or lagging with a phase angle of $2 \pi / n$ with respect to $M_{i s}(x)$. Although in this work, $M_{(i+1) s}(x)$ is lagging $M_{i s}(x)$, either way (lagging or leading) will result in compensating the zero mutual inductance points. Equation (2) satisfies with any number of phases. There is only one exception if $n=2$ where the phase-shift between two adjacent phases is $\pi / 2$ instead of $\pi$. This is to guarantee the null points of $M_{1 s}(x)$ and $M_{2 s}(x)$ do not overlap.

$$
\left\{\begin{array}{c}
M_{1 s}(x)=M_{o} \sin \left(\frac{2 \pi x}{l_{o}}\right) \\
M_{2 s}(x)=M_{o} \sin \left(\frac{2 \pi x}{l_{o}}-\frac{2 \pi}{n}\right) \\
\vdots \\
M_{i s}(x)=M_{o} \sin \left[\frac{2 \pi x}{l_{o}}-(i-1) \frac{2 \pi}{n}\right] \\
\vdots \\
M_{n s}(x)=M_{o} \sin \left[\frac{2 \pi x}{l_{o}}-(n-1) \frac{2 \pi}{n}\right]
\end{array}\right.
$$

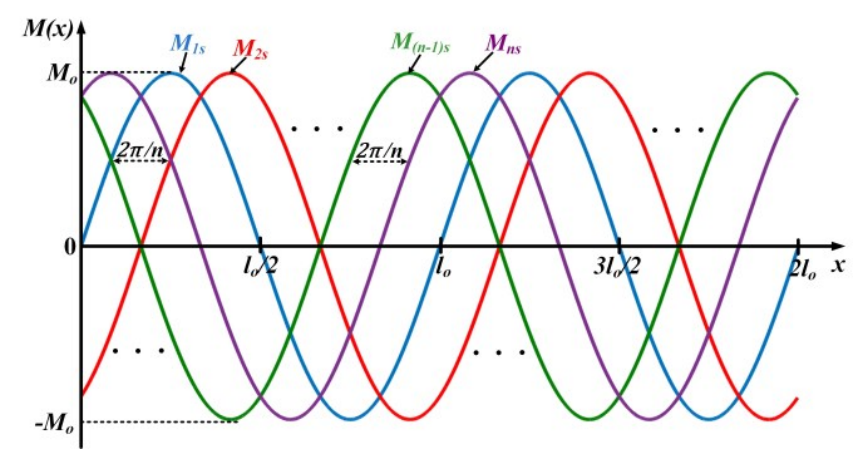

Fig. 4 Expected spatial distribution of mutual inductances for the proposed multiple transmitters

In order to obtain evenly distributed $M_{i s}(x)$ as shown in (2), the proposed $n$ transmitters is structured as depicted in Fig. 5. The proposed transmitter is based on I-type ferrite shape as presented in [12]. As discussed above, ( $n-$ 1) additional mutual inductances are evenly distributed over the length of $l_{o}$. Furthermore, in the proposed system, each original core of the conventional single transmitter (i.e. Fig. $5 \mathrm{a}$ ) is divided into $n$ small cores (Fig. 5b). These small cores dimensions are adjustable and determined by the application requirements. Please note that if the number of phases is an even number, then the original core can be divided into either $0.5 * n$ or $n$ small cores. It is worth noting that two adjacent maximum mutual inductance points occur between a distance of $l_{o} / 2 n$ with the amplitude value of $M_{o}$ (either sign: positive or negative). 
In addition, as the multiple transmitter windings of the proposed system are placed close to each other, there will be crossing mutual inductance between them. These cause higher currents stresses through the inverter switches as well as resonant components of $L_{i a}$ and $C_{i a}$ and have destructive effects on the inverter switches [28]. To alleviate this effect, a small capacitor is connected in series with each transmitter to cancel the induced voltages caused by the crossing coupling (as shown in Fig. 9).

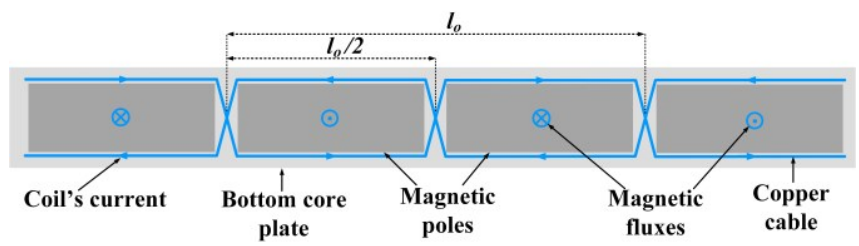

(a)

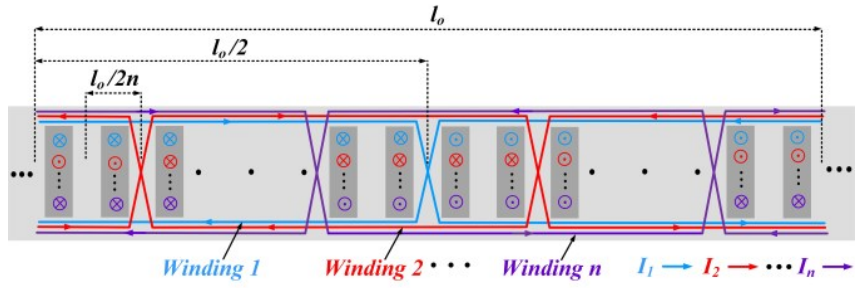

(b)

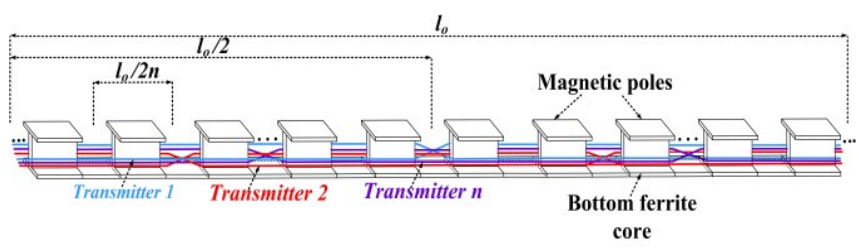

(c)

Fig. 5 Layout configuration of (a) Conventional single transmitter [12] (b) Top view and (c) Side view of the proposed multiple transmitters

\section{Different winding methods to reduce copper wire length}

In order to reduce the cost of the system implementation as well as the associated losses, the transmitter can be configured in different layouts to reduce the required copper. As an example, this Section presents two different winding methods for the proposed multiphase transmitters. The first winding method shown in Fig. 6a is to wind the copper wire from the first to the end poles while the second method is to wind the copper wire around individual poles, which is presented in Fig. 6b. Although the proposed transmitter presented in Section II.C uses three windings, however, for simplicity only one winding is illustrated in Fig. 6(a) and (b) in this section. The pole's length in this Section is of $\left(\frac{l_{o}}{2}-d_{p}\right)$ which consists of three smaller poles.

For the first and second winding method, the total lengths of copper wire $l_{1}$ and $l_{2}$ are given in (3) and (4) respectively:

$$
l_{1} \approx\left(l_{o}-2 d_{p}\right) N_{t u} N_{p o}+2 N_{t u}\left(N_{p o}-1\right) \sqrt{d_{p}^{2}+\frac{w_{p}^{2}}{4}}
$$

$$
\begin{array}{r}
l_{2} \approx\left(l_{o}-2 d_{p}\right) N_{t u} N_{p o}+t_{p}\left(N_{t u}-1\right) N_{p o} \\
+2\left(N_{p o}-1\right) \sqrt{d_{p}^{2}+\frac{w_{p}^{2}}{4}}
\end{array}
$$

Where $N_{p o}$ is number of poles and $N_{t u}$ is number of turns.

Therefore, the required copper for the proposed transmitter is calculated using (3) and (4) and presented in Fig.6(c) and (d). Even though the difference is not considerable if $N_{p o}$ and $N_{t u}$ are of small values, however the second methods saves up to $10 \%$ as compared to the first arrangement when $N_{p o}=$ $N_{t u}=8$. Therefore, second method has be chosen to implement the proposed transmitter.

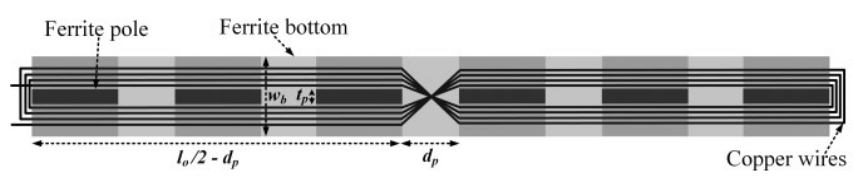

(a)

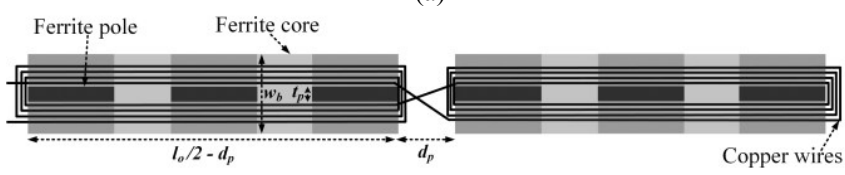

(b)

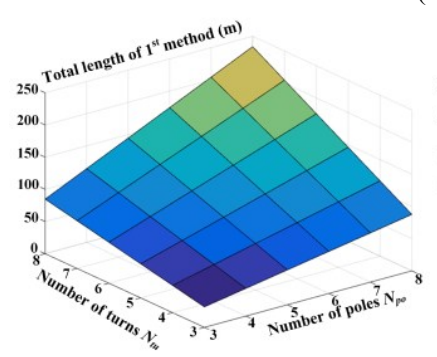

(c)

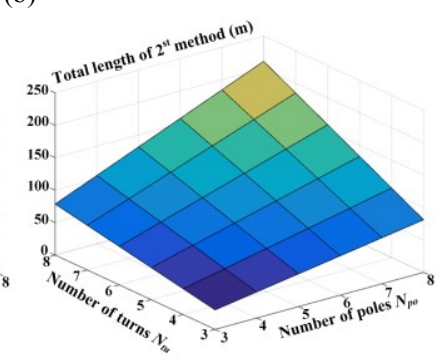

(d)
Fig. 6 Copper winding methods for the proposed multiphase transmitters (a) First method, (b) Second method. Comparison of the total copper wire lengths for three-phase system (c) First method (d) Second method.

\section{Conditions of achieving constant output power}

The open-circuit induced voltage $V_{s}$ on the receiver can be expressed by:

$$
V_{s}=j \omega \sum_{i=1}^{n} M_{i s}(x) I_{i}
$$

Where $I_{i}$ is the current through transmitter $i$ and $M_{i s}(x)$ is the mutual inductance between transmitter $i$ and the receiver

Assuming the inverter produces equal voltages (i.e. with phase shift of $\frac{2 \pi}{n}$ ) across each resonant tank, the currents through transmitter windings can be expressed by:

$$
\left\{\begin{array}{c}
I_{1}=I_{o} e^{j 0} \\
I_{2}=I_{o} e^{j \frac{-2 \pi}{n}} \\
\vdots \\
I_{i}=I_{o} e^{j(i-1) \frac{-2 \pi}{n}} \\
\vdots \\
I_{n}=I_{o} e^{j(n-1) \frac{-2 \pi}{n}}
\end{array}\right.
$$

Consequently, $V_{S}$ can be further expressed as follows: 
$\left|V_{S}\right|=\omega\left|\sum_{i=1}^{n} M_{o} \sin \left(\frac{2 \pi x}{l_{o}}-(i-1) \frac{2 \pi}{n}\right) I_{o} e^{j(i-1)\left(\frac{-2 \pi}{n}\right)}\right|$

$\left|V_{s}\right|=\omega M_{o} I_{o} *$

$\left|\sum_{i=1}^{n}\left\{\frac{e^{j\left[\frac{2 \pi x}{l_{o}}-(i-1) \frac{2 \pi}{n}\right]}-e^{-j\left[\frac{2 \pi x}{l_{o}}-(i-1) \frac{2 \pi}{n}\right]}}{2 j}\right\} e^{j(i-1)\left(\frac{-2 \pi}{n}\right)}\right|$

$\left|V_{S}\right|=\frac{\omega M_{o} I_{o}}{2}\left|\sum_{i=1}^{n}\left[e^{j \frac{2 \pi x}{l_{o}}-j(i-1) \frac{4 \pi}{n}}-e^{-j \frac{2 \pi x}{l_{o}}}\right]\right|$

$\left|V_{s}\right|=\frac{\omega M_{o} I_{o}}{2}\left|e^{j \frac{2 \pi x}{l_{o}}} \sum_{i=1}^{n} e^{-(i-1) \frac{4 \pi}{n}}-e^{-j \frac{2 \pi x}{l_{o}}}\right|$

Where:

$$
\begin{aligned}
\sum_{i=1}^{n} e^{-j(i-1) \frac{4 \pi}{n}}= & e^{0 j}+e^{-j \frac{4 \pi}{n}}+e^{-j \frac{8 \pi}{n}}+e^{-j \frac{12 \pi}{n}} \\
& +\cdots+e^{-j \frac{(n-1) 4 \pi}{n}} \\
& =1+Z_{1}+Z_{2}+Z_{3}+\cdots+Z_{n-1}
\end{aligned}
$$$$
\text { In which: }\left\{\begin{array}{c}
Z_{1}=e^{-j \frac{4 \pi}{n}} \\
Z_{2}=e^{-j \frac{8 \pi}{n}}=Z_{1}^{2} \\
Z_{3}=e^{-j \frac{12 \pi}{n}}=Z_{1}^{3} \\
\vdots \\
Z_{n-1}=e^{-j \frac{(n-1) 4 \pi}{n}}=Z_{1}^{n-1}
\end{array}\right.
$$

Therefore, the sum in (8) is rewritten as (10) with attenuation that $Z_{1}^{n}=e^{-j \frac{4 \pi}{n} n}=\cos (-4 \pi)+j \sin (-4 \pi)=1$

$$
\begin{aligned}
\sum_{i=1}^{n} e^{-j(i-1) \frac{4 \pi}{n}}=1 & +Z_{1}+Z_{2}+Z_{3}+\cdots+Z_{n-1} \\
& =1+Z_{1}+Z_{1}^{2}+Z_{1}^{3}+\cdots+Z_{1}^{n-1} \\
& =\frac{1-Z_{1}^{n}}{1-Z_{1}}=0
\end{aligned}
$$

Considering $\left|e^{-j \frac{2 \pi x}{l_{o}}}\right|=1$, the final expression of $\left|V_{S}\right|$ is given as:

$$
\begin{aligned}
\left|V_{S}\right|=\frac{\omega M_{o} I_{o}}{2} \mid 0 & -n e^{-j \frac{2 \pi x}{l_{o}}}\left|=\frac{n \omega M_{o} I_{o}}{2}\right| e^{-j \frac{2 \pi x}{l_{o}}} \mid \\
= & \frac{n \omega M_{o} I_{o}}{2}
\end{aligned}
$$

At this point, the proposed system consisting of multiple transmitter windings can be simplified as only one transmitter combining with receiver as showed in Fig. 7. In the simplified model, $M$ can be seen as the equivalent mutual inductance between primary and secondary side which is defined as a half of multiplication between the number of transmitters $n$ and amplitude of each mutual inductances $M_{o}$. We also assume that self-inductance of each transmitter is the same so that the equivalent transmitter has its inductance value of $L_{p}$, in which $L_{p}=L_{1}=L_{2}=\cdots=L_{n}$. Finally, the equivalent transmitter current amplitude $I_{p}$ is equal to $I_{o}$ so that $V_{S}$ can be expressed as Eq. (11). It is also noted that the phase of $I_{p}$ does not matter here and constant $\left|V_{s}\right|$ can be attained with any phase value. The equivalent model helps to simplify required calculation and design procedure. According to (11), the induced voltage is constant regardless of receiver's position if adopting the transmitter's layout with expression of mutual inductances in (2) and condition for transmitter's current is shown in (6). Higher value of $\left|V_{s}\right|$ and corresponding power are realized with increase in the number of phase $n$.

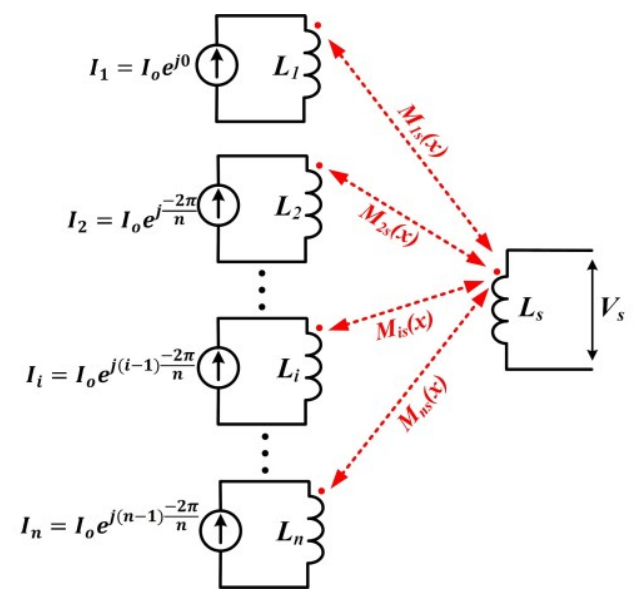

(a)

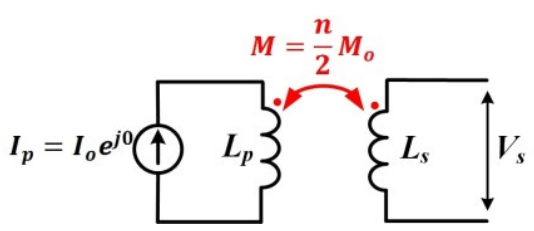

(b)

Fig. 7 (a) Model of the proposed multiple transmitters (only coupled-coil part), (b) the simplified form of model in Fig. 7(a).

\section{IlLuStRAtive Design EXAMPLE OF THREE-PHASE WDC SYSTEM}

The proposed multi-phase system is validated with an illustrative example based on a three-phase system in this Section. The circuit configuration is shown in Fig. 8 in which a conventional three-phase inverter is adopted to the primary side. The proposed layout in Fig. 5 is applied with $n=3$ and the three transmitters are shown in Fig. 12. Mutual inductance distributions are depicted in Fig. 9 and phase difference between two consecutive transmitter is set to $2 \pi / 3$.

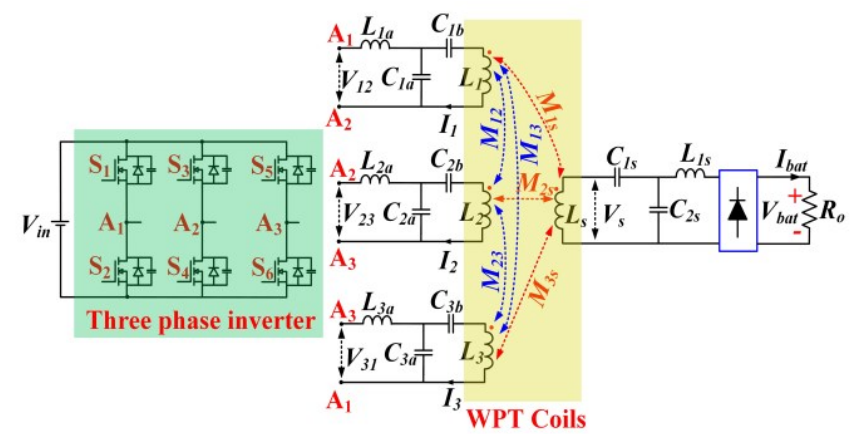

Fig. 8. The circuit configuration of three-phase dynamic charging system 


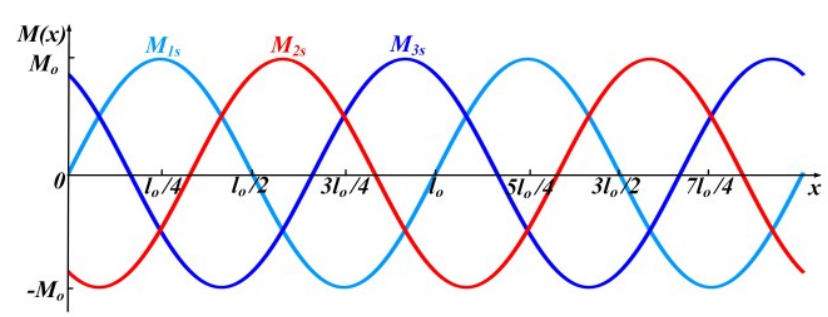

Fig. 9. Spatial distribution of mutual inductances of three-phase transmitters system in Fig. 12

Therefore, mutual inductances equations are shown in (12).

$$
\left\{\begin{array}{c}
M_{1 s}(x)=M_{o} \sin \left(\frac{2 \pi x}{l_{o}}\right) \\
M_{2 s}(x)=M_{o} \sin \left(\frac{2 \pi x}{l_{o}}-\frac{2 \pi}{3}\right) \\
M_{3 s}(x)=M_{o} \sin \left(\frac{2 \pi x}{l_{o}}-\frac{4 \pi}{3}\right)
\end{array}\right.
$$

Firstly the output voltage of three-phase inverter can be depicted as (13):

$$
\left\{\begin{array}{c}
V_{12}=\frac{2 \sqrt{3}}{\pi} V_{i n} e^{j 0} \\
V_{23}=\frac{2 \sqrt{3}}{\pi} V_{i n} e^{j\left(-\frac{2 \pi}{3}\right)} \\
V_{31}=\frac{2 \sqrt{3}}{\pi} V_{i n} e^{j\left(-\frac{4 \pi}{3}\right)}
\end{array}\right.
$$

To simplify control requirements of transmitter currents $I_{i}(i=\overline{1,3})$, resonance of $L_{i a}$ and $C_{i a}(i=\overline{1,3})$ is adopted at $\omega_{o}$ as shown in (14) to keep a constant amplitude of the transmitter's current. Therefore, $I_{i}$ are expressed in (15).

$$
\begin{gathered}
\omega_{o}^{2}=\frac{1}{L_{i a} C_{i a}}(i=\overline{1,3}) \\
\left\{\begin{array}{c}
I_{1}=V_{12} \omega_{o} C_{1 a} e^{j\left(\frac{-\pi}{2}\right)}=\frac{2 \sqrt{3}}{\pi} V_{i n} \omega_{o} C_{1 a} e^{j\left(\frac{-\pi}{2}\right)}=I_{o} e^{j\left(\frac{-\pi}{2}\right)} \\
I_{2}=V_{23} \omega_{o} C_{2 a} e^{j\left(\frac{-\pi}{2}\right)}=\frac{2 \sqrt{3}}{\pi} V_{i n} \omega_{o} C_{2 a} e^{j\left(\frac{-7 \pi}{6}\right)}=I_{o} e^{j\left(\frac{-7 \pi}{6}\right)} \\
I_{3}=V_{31} \omega_{o} C_{3 a} e^{j\left(\frac{-\pi}{2}\right)}=\frac{2 \sqrt{3}}{\pi} V_{i n} \omega_{o} C_{3 a} e^{j\left(\frac{-11 \pi}{6}\right)}=I_{o} e^{j\left(\frac{-11 \pi}{6}\right)}
\end{array}\right.
\end{gathered}
$$

Fig. 10 presents the primary LCC tank considering magnetic interferences between three transmitters. The total induced voltages within the transmitters 1,2 and 3 namely $V_{T 1}, V_{T 2}$ and $V_{T 3}$ which are caused by the other transmitters are given by (16). It is noted that $M_{12}=M_{21}, M_{13}=M_{31}$ and $M_{23}=M_{32}$. These crossing induced voltages do not affect the receiver's induced voltage $V_{s}$ and output power $P_{o}$ but cause higher current stresses on inverter and the resonant components $L_{i a}$ and $C_{i a}$.

$$
\left\{\begin{array}{l}
V_{T 1}=j \omega_{o} M_{12} I_{2}+j \omega_{o} M_{13} I_{3} \\
V_{T 2}=j \omega_{o} M_{21} I_{1}+j \omega_{o} M_{23} I_{3} \\
V_{T 3}=j \omega_{o} M_{31} I_{1}+j \omega_{o} M_{32} I_{2}
\end{array}\right.
$$

To eliminate the crossing induced voltages on each transmitters, compensated capacitors $C_{c o m 1}, C_{c o m 2}$ and $C_{\text {com3 }}$ are added into each transmitter producing a reversed voltage against $V_{T 1}, \quad V_{T 2}$ and $V_{T 3}$. From experimental measurement, all crossing mutual inductances have the same negative value because of the layout's structure. Therefore, we can set $M_{12}=M_{21}=M_{13}=M_{31}=M_{23}=M_{32}=M_{\text {cros }}$ in which $M_{\text {cros }}$ is a negative number. Further derivations have been made with (16) and $V_{T 1}, V_{T 2}$ and $V_{T 3}$ can be expressed depending on $M_{\text {cros }}$ as follows.

$$
\left\{\begin{array}{c}
V_{T 1}=j \omega_{o} M_{\text {cros }} I_{1} e^{j \frac{2 \pi}{3}}+j \omega_{o} M_{\text {cros }} I_{1} e^{j \frac{4 \pi}{3}} \\
\quad=-j \omega_{o} M_{\text {cros }} I_{1}=j \omega_{o}\left|M_{\text {cros }}\right| I_{1} \\
V_{T 2}=j \omega_{o} M_{\text {cros }} I_{2} e^{j \frac{-2 \pi}{3}}+j \omega_{o} M_{\text {cros }} I_{2} e^{j \frac{2 \pi}{3}} \\
\quad=-j \omega_{o} M_{\text {cros }} I_{2}=j \omega_{o}\left|M_{\text {cros }}\right| I_{2} \\
V_{T 3}=j \omega_{o} M_{\text {cros }} I_{3} e^{j \frac{-4 \pi}{3}}+j \omega_{o} M_{\text {cros }} I_{3} e^{j \frac{-2 \pi}{3}} \\
=-j \omega_{o} M_{\text {cros }} I_{3}=j \omega_{o}\left|M_{\text {cros }}\right| I_{3}
\end{array}\right.
$$

Voltages on compensated capacitors (i.e. $V_{\text {Ccom } 1}$, $\left.V_{\text {Ccom } 2}, V_{\text {Ccom } 3}\right)$ should be equal in magnitude and reversed in phase with $\left(V_{T 1}, V_{T 2}, V_{T 3}\right)$ to effectively cancel these above crossing induced voltages.

$$
\left\{\begin{array}{l}
V_{C \operatorname{com} 1}=\frac{1}{j \omega_{o} C_{c o m} 1} I_{1}=-V_{T 1} \\
V_{C c o m 2}=\frac{1}{j \omega_{o} C_{c o m}} I_{2}=-V_{T 2} \\
V_{C c o m 3}=\frac{1}{j \omega_{o} C_{c o m}} I_{3}=-V_{T 3}
\end{array}\right.
$$

Therefore, three compensated capacitors can be calculated based on (19). These capacitors have the same value and depend only on crossing mutual inductance and operating frequency.

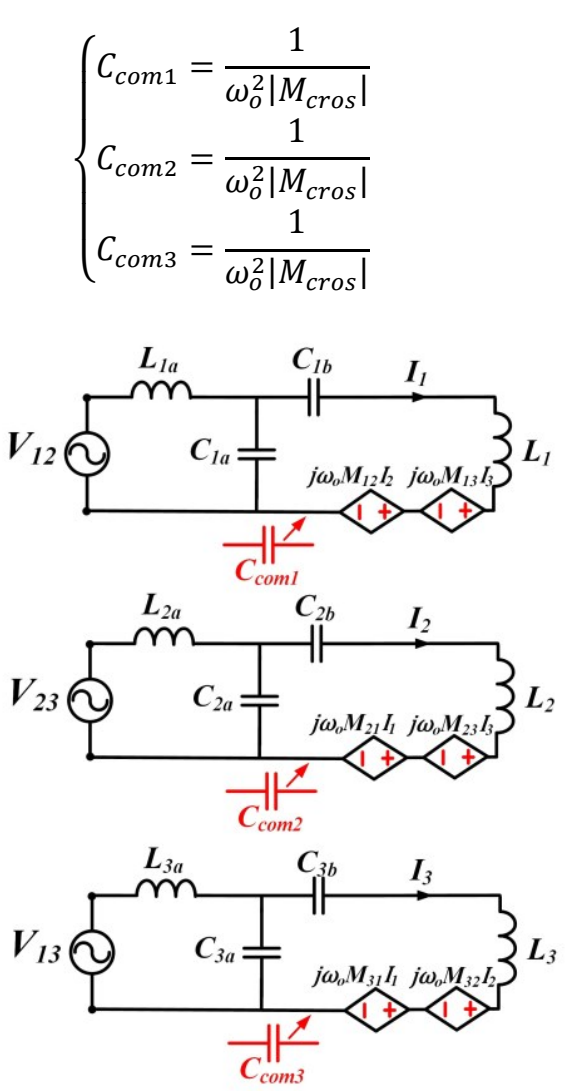

Fig. 10. Primary LCC tanks considering magnetic interferences

Finally, $C_{\text {com } 1}, C_{\text {com } 2}$ and $C_{\text {com } 3}$ can be integrated into $C_{1 b}$, $C_{2 b}$ and $C_{3 b}$ to become a single serial capacitor for each 
phase. These serial capacitors are determined by (20). In Section $\mathrm{V}$, experimental results are presented to compare between including and not including these compensated capacitors.

$$
\left\{\begin{array}{l}
C_{1 b}=\frac{1}{\omega_{o}^{2}}\left(\frac{1}{L_{1}-L_{1 a}}+\frac{1}{\left|M_{\text {cros }}\right|}\right) \\
C_{2 b}=\frac{1}{\omega_{o}^{2}}\left(\frac{1}{L_{2}-L_{2 a}}+\frac{1}{\left|M_{\text {cros }}\right|}\right) \\
C_{3 b}=\frac{1}{\omega_{o}^{2}}\left(\frac{1}{L_{3}-L_{3 a}}+\frac{1}{\left|M_{\text {cros }}\right|}\right)
\end{array}\right.
$$

In an dynamic charging system, constant current charge is preferable than constant voltage charge because EV battery's state of charge (SoC) is rarely reached to fully charged [4]. Therefore another LCC tank is constructed at secondary side tank to produce output current source as shown in Fig. 11. Capacitors $C_{1 s}$ is connected in series with $L_{s}$ while $C_{2 s}$ and $L_{1 s}$ are additional paralel capacitor and inductor for each secondary tank. According to equivalent circuit on Fig. 11, DC output current is depicted as (21) if the resonant tank at secondary side is designed as (22) and (23). In (21), $M_{i s}$ and $I_{i}(i=\overline{1,3})$ can be found in (12) and (15) respectivelly.

$$
\begin{aligned}
& I_{\text {bat }}=\frac{2}{\pi} \omega_{o}^{2} C_{2 s}\left|\sum_{i=1}^{3} M_{i s} I_{i}\right|=\frac{3 \omega_{o}^{2} C_{2 s} M_{o} I_{o}}{\pi} \\
& =\frac{6 \sqrt{3}}{\pi^{2}} \omega_{o}^{3} C_{i a} C_{2 s} M_{o} V_{i n} \\
& j \omega_{o} L_{s}+\frac{1}{j \omega_{o} C_{1 s}}+\frac{1}{j \omega_{o} C_{2 s}}=0 \\
& j \omega_{o} L_{1 s}+\frac{1}{j \omega_{o} C_{2 s}}=0
\end{aligned}
$$

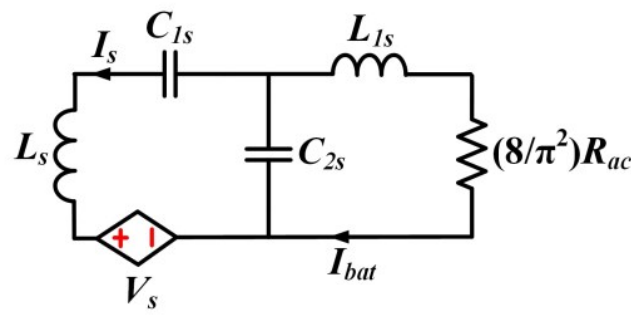

Fig. 11. $A C$ Equivalent circuit of secondary circuit

Combining (14), (20), (22) and (23), the equation of the resonant frequency $\omega_{o}$ can be determined as (24), in which $\omega_{o}$ is regardless of both load condition $\left(R_{o}\right)$ and mutual inductances between transmitters and receiver $\left(M_{1 s}, M_{2 s}\right.$ and $\left.M_{3 s}\right)$.

$$
\begin{gathered}
\omega_{o}^{2}=\frac{1}{L_{i a} C_{i a}}=\frac{1}{C_{i b}} \\
\left(\frac{1}{L_{i}-L_{i a}}+\frac{1}{\left|M_{\text {cros }}\right|}\right)=\frac{1}{L_{1 s} C_{2 s}} \\
=\frac{1}{C_{1 s}}\left(\frac{1}{L_{s}-L_{1 s}}\right)(i=\overline{1,3})
\end{gathered}
$$

The DC output voltage and power are presented in (25) and (26) adopting $R_{o}$ which is equivalent battery's impedance. It needs to emphasize that if switching frequency $\omega_{o}$ and secondary side capacitor $C_{2 s}$ are assumed to be constant, then each load output power depends only on the multiplication $M_{o} I_{o}$. Obviously, it can be seen that $P_{o}$ is constant and regardless to receiver's position.

$$
\begin{gathered}
V_{b a t}=I_{b a t} R_{o}=\frac{6 \sqrt{3}}{\pi^{2}} \omega_{o}^{3} C_{i a} C_{2 s} M_{o} V_{i n} R_{o} \\
P_{o}=I_{b a t}^{2} R_{o}=\left(\frac{6 \sqrt{3}}{\pi^{2}} \omega_{o}^{3} C_{i a} C_{2 s} M_{o} V_{i n}\right)^{2} R_{o}
\end{gathered}
$$

\section{OPTIMIZED DESIGN OF MAGNETIC COUPLER}

\section{A. Design of Three-phase Transmitters}

This section presents the transmitters magnetic design aiming for maximum output power of $3 \mathrm{~kW}$ (scale down value). Several simulations are conducted using MAXWELL 3D software to select the optimal parameters for transmitters, which are presented in Fig. 12. They consists of the ferrite pole sizes (thickness $t_{p}$, distance $d_{p}$, height $h_{p}$, length $l_{p}$ and plate width $w_{p}$ ), ferrite bottom sizes (width $w_{b}$ and thickness $t_{b}$ ) as well as number of turns for three transmitter's windings $N_{1}, N_{2}$ and $N_{3}$. As three transmitter are identical, we consider only one transmitter in simulation model which is shown in Fig. 13a for simplicity. The purpose of simulation is to determine the optimal parameters so that the maximum of magnetic flux density $B$ can be attained at the center of every three poles (as shown in Fig. 12). With an appropriate receiver design, maximum of $B$ also means maximum coupling coefficient and the highest power delivery as well as high efficiency. Simultaneously, we try to minimize the ferrite core's volume and cable's length but the system still needs to satisfy the power delivery requirement and avoid the core's saturation. In order to produce a homogeneous magnetic flux along driving direction, number of turns should be selected equally for three windings and all three transmitter's currents are set as maximum of 20 A. The maximum air-gap between transmitter and receiver are selected as $15 \mathrm{~cm}$

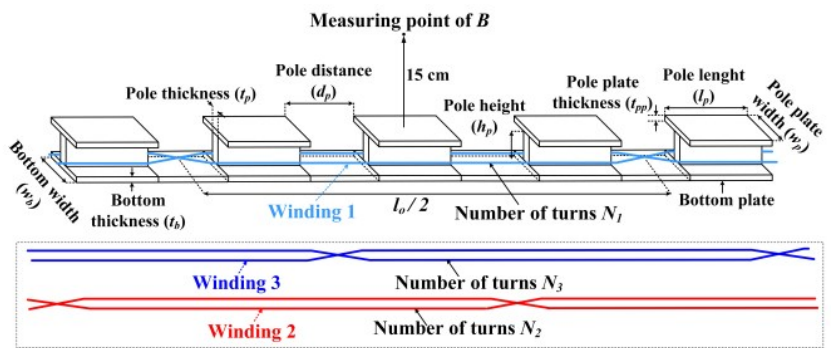

Fig. 12 Design parameters of three-phase primary transmitters

Thickness and width of pole and bottom plates are selected to prevent saturation problems. Thereout, thickness values have very limited effect again magnetic field level. Fig. 13b presents distribution of magnetic flux on ferrite core with bottom thickness $\left(t_{b}\right)=$ pole plate thickness $\left(t_{p p}\right)=0.5 \mathrm{~cm}$ and pole thickness $\left(t_{p}\right)=1.5 \mathrm{~cm}$. According to that the maximum magnetic flux density of $0.152 \mathrm{~T}$ occurs around the crossing winding areas on the core bottom. In this work, the ferrite core of PC47 by TDK Electronics is selected and their saturated magnetic flux density $B_{s}$ is founded as $0.54 \mathrm{~T}$ at 25 ${ }^{\circ} \mathrm{C}$ [29]. Therefore, we can guarantee of no saturation for the primary core with output power level of $3 \mathrm{~kW}$ and transmitter current of $20 \mathrm{~A}$. Note that it is possible to implement smaller thickness values, however, values below $0.5 \mathrm{~cm}$ are difficult to achieve practically due to the physical cutting process of ferrite . The width is selected as small as possible to reduce the width of the rail, then the constructed cost and pedestrian 
EMI contamination can be reduced. Here, the widths of both bottom and pole plate are selected as $12 \mathrm{~cm}$.

The remaining three design parameters are : pole distance $\left(d_{p}\right)$, pole length $\left(l_{p}\right)$ and number of turns $(N)$. The relationship between $d_{p}$ and $l_{p}$ can be found in (27) with $l_{o}$ is fixed based on system's requirements, which is 2.4 meters in this work. Therefore, only $d_{p}$ needs to be found and $l_{p}$ will follow according to (27). Fig. 13c presents the relationship between normalized magnetic coupling againts pole distance $d_{p}$. It is noted that the measurement point are located right above the center of each group of 3 ferrite poles as shown in Fig. 12. When $d_{p}$ varies in a range from 5 to $22.5 \mathrm{~cm}$, then normalized value of magnetic flux density reduces accordingly. It can be seen that the maximum magnetic flux density value can be achieved at pole distances from 5 to $7.5 \mathrm{~cm}$. This fact can be explained by deriving the magnetic flux equations depending winding's width and length [30]. Value $d_{p}$ of $7.5 \mathrm{~cm}$ is selected in this work because $5-\mathrm{cm}$ value creates a quite small space which may not enough incooperate a large number of winding turns.

$$
d_{p}+l_{p}=\frac{l_{o}}{6}
$$

Fig. 13d demonstrates how magnetic flux density $B_{l}$ varies according to number of turns for one single winding $N_{l}$. Theoretically, $B_{l}$ becomes linear with $N_{l}$ and while number of turns increases from 2 to $6, B_{l}$ rises from 31 to $93 \mu \mathrm{T}$ as a result. Higher number of turns result in higher power delivery capability, however, it also increases the total copper wire's length, transmitter inductance and pedestrian EMI contamination. A number of 4 turns is finally selected and Litz wire (600 strands-AWG 38) is adopted to reduce conduction losses on windings. After several trial and errors in both simulations and experiments final parameters are selected and depicted in TABLE I to meet with system requirements.

TABLE I

PARAMETER VALUES OF PRIMARY TRANSMITTERS

\begin{tabular}{|c|c|c|}
\hline$t_{b}$ & Bottom thickness & $0.5 \mathrm{~cm}$ \\
\hline$w_{b}$ & Bottom width & $12 \mathrm{~cm}$ \\
\hline$t_{p}$ & Pole thickness & $1.5 \mathrm{~cm}$ \\
\hline$d_{p}$ & Pole distance & $7.5 \mathrm{~cm}$ \\
\hline$h_{p}$ & Pole height & $4 \mathrm{~cm}$ \\
\hline$l_{p}$ & Pole length & $12 \mathrm{~cm}$ \\
\hline$w_{p}$ & Pole plate width & $12 \mathrm{~cm}$ \\
\hline$t_{p p}$ & Pole plate thickness & $0.5 \mathrm{~cm}$ \\
\hline$d$ & Air gap & $15 \mathrm{~cm}$ \\
\hline & $\begin{array}{l}\text { Number of ferrite poles } \\
\text { (individual pole) }\end{array}$ & 12 \\
\hline & Number of winding & 3 \\
\hline$N_{1}, N_{2}, N_{3}$ & Number of turns for each winding & 4 \\
\hline $2 l_{o}$ & Total transmitter's length & 2.4 meters \\
\hline$I_{1}, I_{2}, I_{3}$ & Transmitter's currents (maximum) & $20 \mathrm{~A}$ \\
\hline
\end{tabular}

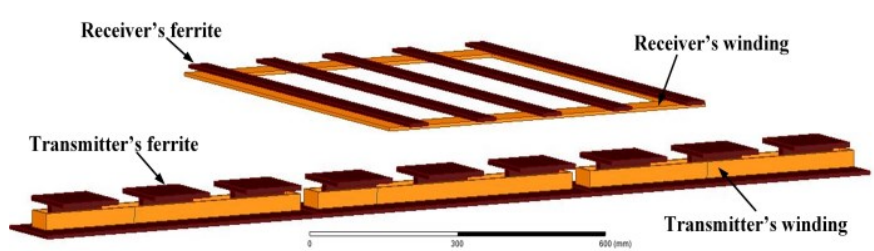

(a)

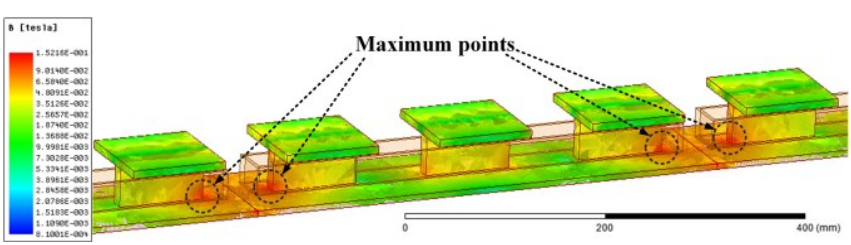

(b)

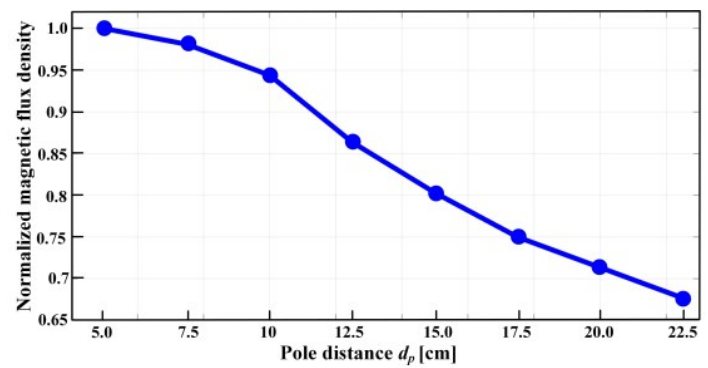

(c)

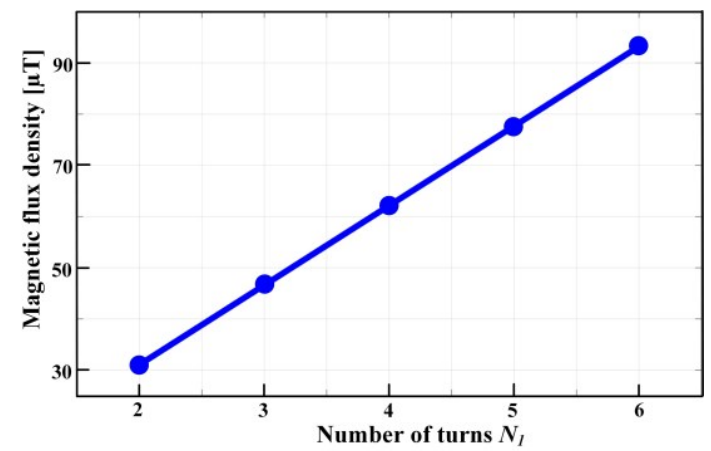

(d)

Fig.13 (a) Simulation model of the proposed transmitters with bottom thickness $t_{b}=0.5 \mathrm{~cm}$, bottom width $w_{b}=12 \mathrm{~cm}$, pole thickness $t_{p}=1.5 \mathrm{~cm}$, pole height $h_{p}=4 \mathrm{~cm}$, pole length $l_{p}=12 \mathrm{~cm}$, pole plate width $w_{p}=12 \mathrm{~cm}$, pole plate thickness $t_{p p}=0.5 \mathrm{~cm}$. Pole distance $d_{p}$ and number of turns $N_{l}$ are varied in simulation (b) Contribution of magnetic flux density on transmitter's ferrite core with $N_{l} I_{l}=80$ A (c) Normalized magnetic flux density depending on the pole distance with $N_{l} I_{l}=80 \mathrm{~A}$ (d) Magnetic flux density depending on number of turns with $d_{p}=7.5 \mathrm{~cm}$.

\section{B. Design of receiver}

After obtaining transmitter's parameters, this section provides the design for receiver's parameters, which include receiver's length $l_{r}$, width $w_{r}$ and number of turns $N_{s}$. The most sensitive parameter as regards the coupling coefficient $k$ is the receiver's length $l_{r}$. Fig. 14a shows result of how coupling coefficient against $l_{r}$ with transmitter parameters on Table I. As shown in Fig. 14a, normalized coupling value increases from 0.05 at $l_{r}=30 \mathrm{~cm}$ and reaches to the highest value when $l_{r}=60 \mathrm{~cm}$ (equal to $l_{o} / 2$ ). If $l_{r}$ goes higher than 60 $\mathrm{cm}$, then $k$ drops significantly to nearly zero at $100 \mathrm{~cm}$. It can be explained by the fact that when $l_{r}<60 \mathrm{~cm}$, then receiver's winding cannot cover entirely the align transmitter winding, therefore, $k$ is always lower than the highest value. For $l_{r}>60$ $\mathrm{cm}$, then receiver is also received magnetic fluxes from other two adjacent transmitter windings which have reversed current directions and create opposite magnetic fluxes as compared to the align winding. Totally, there is a flux reduction on receiver when $l_{r}>60 \mathrm{~cm}$ as compared to the highest case. More seriously, the total flux on receiver can be 
cancelled completely if the total flux coming in equals to the flux coming out receiver. It results in no coupling between two sides and no induced voltage in the receiver winding.

Fig. $14 \mathrm{~b}$ and $14 \mathrm{c}$ provides simulation results of coupling coefficient under different receiver's width and lateral misalignments values. The coupling value $k$ needs to be high as much as possible at different lateral misalignment conditions. Fig. $14 \mathrm{~b}$ provides coupling values regarding different receiver's widths $w_{r}$ under no misalignment. It shows that $k$ increases from 0.062 to nearly 0.1 when $w_{r}$ rises from 10 to $30 \mathrm{~cm}$. However, if $w_{r}$ continues to increases up to $70 \mathrm{~cm}$ then $k$ will slightly reduce. Under lateral misalignment conditions, it can be investigated in Fig. 14c that how reduction of coupling regarding different receiver's width values. If misalignment level equals to $30 \mathrm{~cm}$, then $k$ will reduce to nearly $0 \%, 30 \%$ and $60 \%$ associating with $w_{r}=50$ , 60 and $70 \mathrm{~cm}$, respectively. Fundamentally, higher $w_{r}$ values enhances coupling and output power under lateral misalignment, however, coupling coefficient is also reduced when increasing $w_{r}$ at perfect align condition. Moreover, $w_{r}$ is also limited by installation space at bottom of vehicle. Considering all above factors, $w_{r}$ is selected as $60 \mathrm{~cm}$ in this work so that output power level can remain at $30 \%$ of maximum power under $30 \mathrm{~cm}$ of lateral misalignment. After selecting receiver's dimensions of $l_{r}=w_{r}=60 \mathrm{~cm}$, then number of turns $N_{s}$ can be estimated as 8 turns based on the required output voltage (i.e. $450 \mathrm{~V}$ ) and operating frequency (i.e. $85 \mathrm{kHz}$ ).

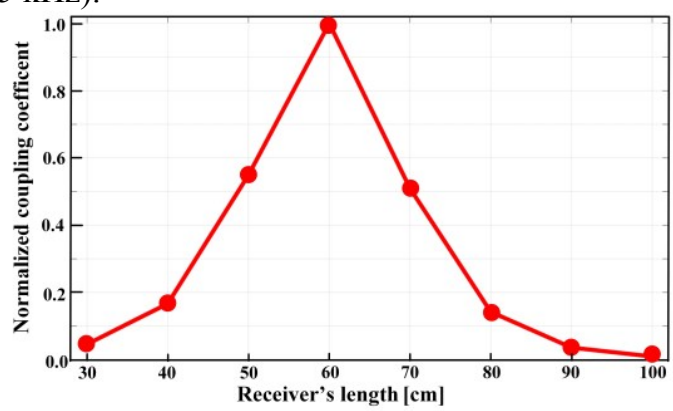

(a)

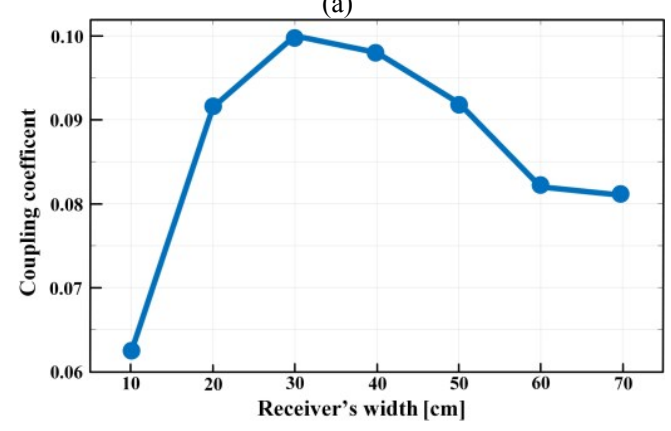

(b)

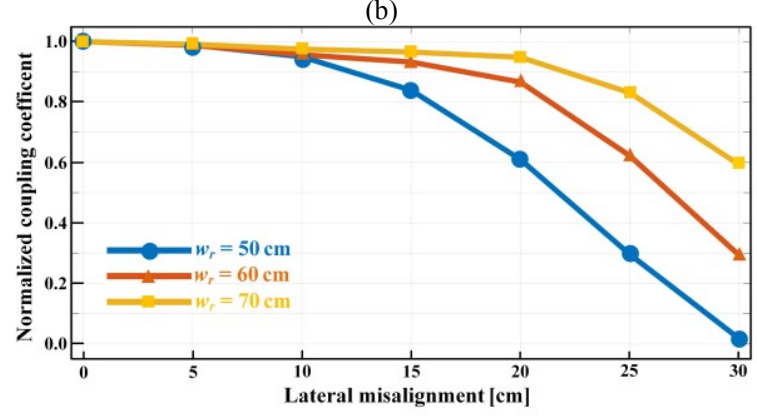

(c)

Fig. 14. Simulation on Maxwell 3D of normalized coupling coefficient with transmitter's parameters from Table I against (a) different receiver's length (b) different receiver's width at no misalignment (c) different lateral misalignment conditions.

\section{EXPERIMENTAL VALIDATION AND DISCUSSIONS}

In order to validate the proposed WDC, a scaled down prototype of $3-\mathrm{kW}$ system is developed in lab as portrayed in Fig. 15. The parameters of the transmitter and receiver are tabulated in Table I. As shown in Fig. 15(b), the transmitter windings are arranged in three layer, which isolated from each other using plastic sheets. Furthermore, Kapton-tapeshield Litz wire is used to further improve the isolation winnings different loops of the same phase's winding. The receiver shown in Fig. 15(c) is constructed using 5-long-bar ferrite core and 8-turn Litz wires. As highlighted in in Section $\mathrm{IV}$, the dimension of the receiver is $60 \mathrm{~cm} \times 60 \mathrm{~cm}$ while the maximum air-gap between the transmitter and receiver is tested at $15 \mathrm{~cm}$. The three-phase inverter is built using $\mathrm{SiC}$ MOSFET, C2M0025120D from Cree while SiC- Schottkydiodes, HFA50PA60 are selected for the rectifier at the output side. Polypropylene film capacitors are chosen for the resonant tank owing to their low equivalent series resistance and high current carrying capability. The specifications of the proposed WDC are summarized in Table II along with the parameters of resonant circuit. Please note that the compensated capacitors $C_{c o m 1}, C_{c o m} 2, C_{c o m} 3$ are adjusted from $76.22 \mathrm{nF}$ in simulation to $66.5 \mathrm{nF}$ in experiment for achieving Zero-Voltage-Switching (ZVS) of all Inverter's switches.

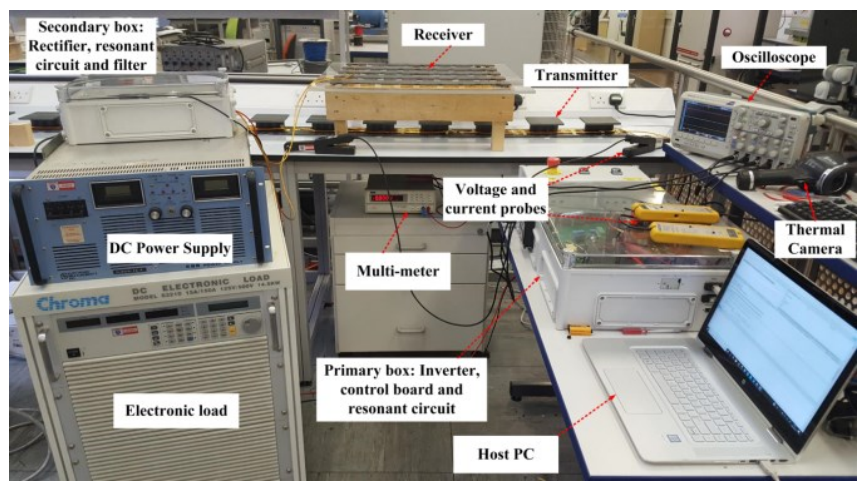

(a)

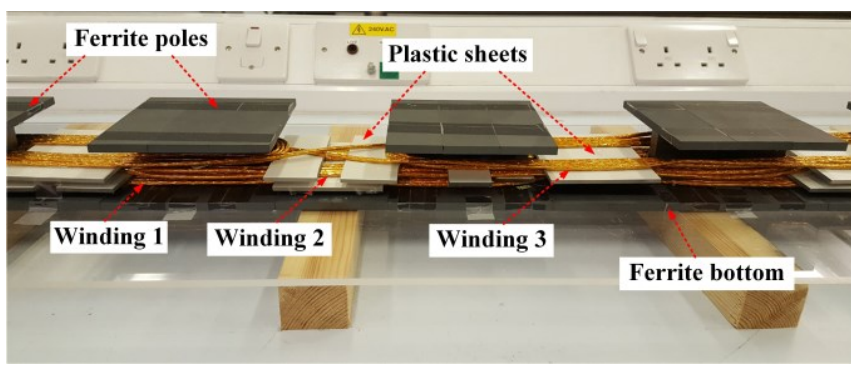

(b)

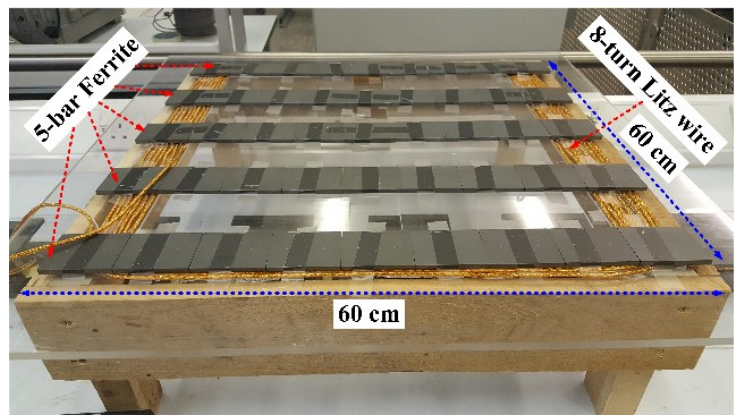

(c)

Fig. 15. (a) Experimental test-rig of the proposed WDC system (b) Threephase transmitter (c) Receiver 
TABLE II

SPECIFICATION AND PARAMETERS OF THE PROPOSED WDC

\begin{tabular}{|c|c|c|c|}
\hline Symbol & Parameter & Simulated values & Practical values \\
\hline$V_{\text {in }}$ & Input voltage & $400 \mathrm{~V}$ & $400 \mathrm{~V}$ \\
\hline$I_{o}$ & Rated output current & $6.5 \mathrm{~A}$ & $6.45 \mathrm{~A}$ \\
\hline$P_{o}$ & Rated output power & $3 \mathrm{~kW}$ & $2.91 \mathrm{~kW}$ \\
\hline$L_{1}, L_{2}, L_{3}$ & Self-inductance of transmitters & $182 \mu \mathrm{H}$ & $178.6 \mu \mathrm{H}, 180.2 \mu \mathrm{H}, 179.6 \mu \mathrm{H}$ \\
\hline$L_{s}$ & Self-inductance of receiver & $118 \mu \mathrm{H}$ & $120.5 \mu \mathrm{H}$ \\
\hline$M_{o}$ & Maximum mutual inductance & $12.6 \mu \mathrm{H}$ & $12.48 \mu \mathrm{H}$ \\
\hline$M_{12}, M_{13}, M_{23}$ & Crossing mutual inductances & $-46 \mu \mathrm{H}$ & $-44.5 \mu \mathrm{H},-45.8 \mu \mathrm{H},-47.1 \mu \mathrm{H}$ \\
\hline$L_{1 a}, L_{2 a}, L_{3 a}$ & Primary additional inductors & $37 \mu \mathrm{H}$ & $36.2 \mu \mathrm{H}, 37.3 \mu \mathrm{H}, 37.5 \mu \mathrm{H}$ \\
\hline$C_{I a}, C_{2 a}, C_{3 a}$ & Primary parallel capacitors & $95 \mathrm{nF}$ & $95.2 \mathrm{nF}, 95.1 \mathrm{nF}, 95.2 \mathrm{nF}$ \\
\hline$C_{1 b}, C_{2 b}, C_{3 b}$ & $\begin{array}{c}\text { Primary series capacitors (without } \\
\text { compensated capacitors) }\end{array}$ & $24.2 \mathrm{nF}$ & $24.2 \mathrm{nF}$ \\
\hline$C_{\text {com } 1}, C_{\text {com } 2}, C_{c o m} 3$ & Primary compensated capacitors & $76.22 \mathrm{nF}$ & $66.5 \mathrm{nF}$ \\
\hline$L_{l s}$ & Secondary additional inductors & $35 \mu \mathrm{H}$ & $36.2 \mu \mathrm{H}$ \\
\hline$C_{2 s}$ & Secondary parallel capacitors & $100 \mathrm{nF}$ & $100.6 \mathrm{nF}$ \\
\hline$C_{l s}$ & Secondary series capacitors & $42.2 \mathrm{nF}$ & $42.5 \mathrm{nF}$ \\
\hline$f$ & Switching frequency & $85 \mathrm{kHz}$ & $85.05 \mathrm{kHz}$ \\
\hline
\end{tabular}

Fig. 16 illustrates key operating waveforms at the primary side circuit. Specifically, Fig. 16(a) depicts the Gate PWM signals, while the output voltages $V_{12}, V_{23}$ and $V_{31}$ can be seen in Fig. 16(b). The corresponding transmitter currents $I_{1}, I_{2}$ and $I_{3}$ are shown in Fig. $16(\mathrm{c})$, where they have the same amplitude and a phase-shift of 120 degrees apart from each other. Fig. 16(d) depicts the measured voltage $V_{d s}$ and current $I_{d s}$ of the MOSFET switches (i.e. $S_{1}, S_{3}$ and $S_{5}$ ) at the rated power. As it can be noticed that turn-on Zero Voltage Switching (ZVS) is achieved for all switches, which leads to a significant reduction in switching losses of the inverter.

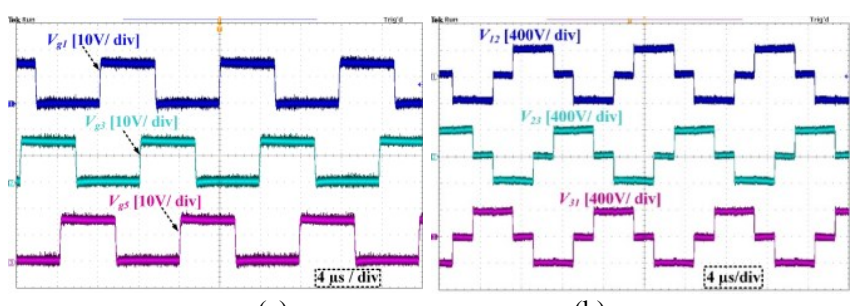

(a)

(b)

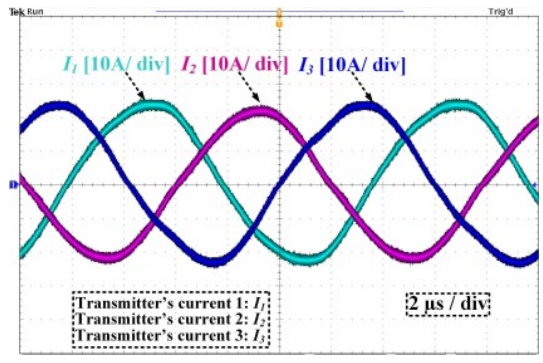

(c)
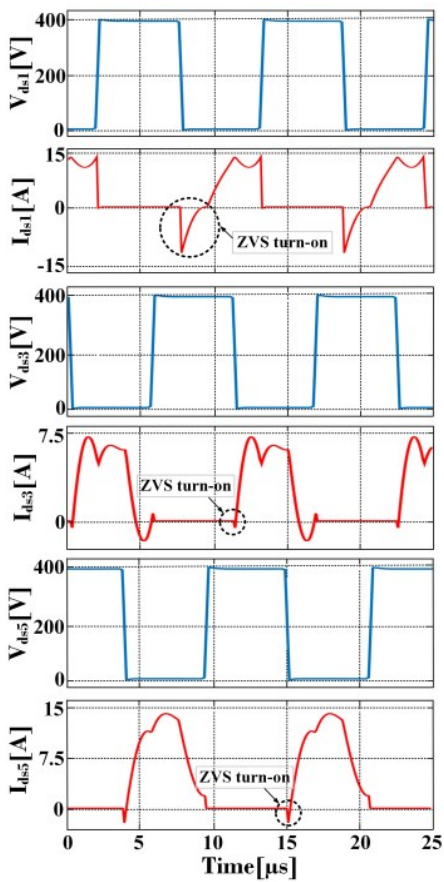

(d)

Fig. 16. Key waveforms at primary side: (a) Gate signal of three-phase inverter, (b) Inverter's voltage (c) Transmitter's currents (d) Inverter switches' voltage $V_{d s}$ and current $I_{d s}$ under the rated load condition (with the receiver's displacement of $60 \mathrm{~cm}$ )

Fig. 17 further demonstrates the operation of the proposed system under different loading conditions (i.e. $17 \Omega, 40 \Omega$ and $70 \Omega$ ) while receiver is in the moving process. Moreover, the 
harvested output power at different positions along the driving direction $x$ as portrayed in Fig. 18. It should be noted that $x$ starts only from $15 \mathrm{~cm}$ and ends at $225 \mathrm{~cm}$ as only cases when the whole receiver is positioned on the transmitter windings are considered.

The power fluctuation factor is defined as $\Delta P=$ $\left(\frac{P_{\max }-P_{\min }}{P_{\max }}\right) * 100 \%$. For this particular experiment, $\Delta P$ are found to be $4.9 \%, 5.6 \%$ and $5.1 \%$ with the load of 17,40 and $70 \Omega$, respectively.

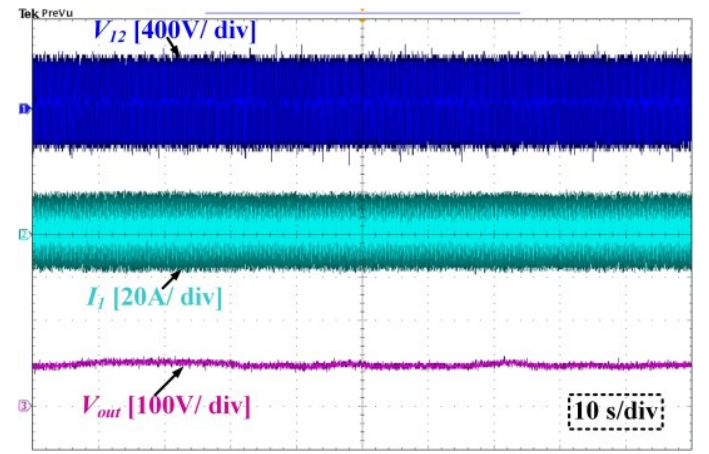

(a)

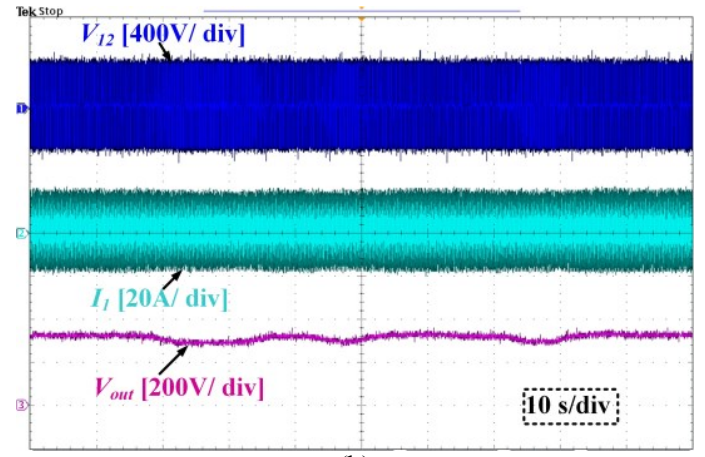

(b)

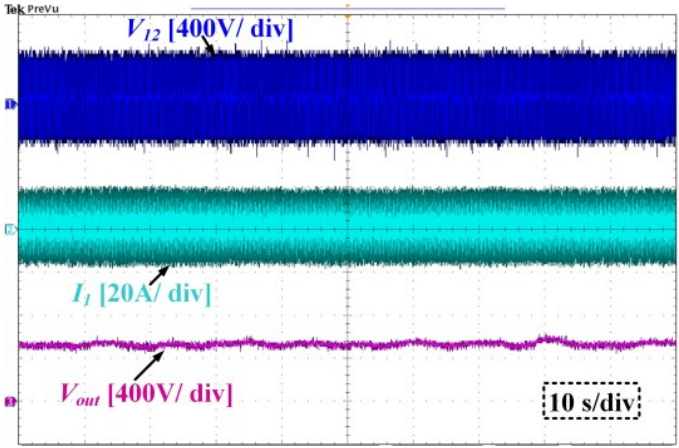

(c)

Fig. 17. Experimental waveforms with different load while receiver moving along driving direction (a) $R_{o}=17 \Omega$, (b) $R_{o}=40 \Omega$ and (c) $R_{o}=70 \Omega$

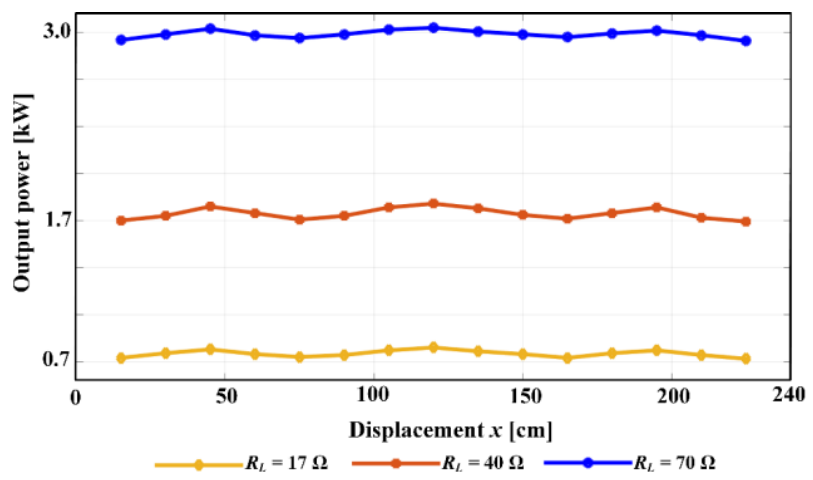

Fig. 18. Measured output power with different load conditions and different receiver positions along the driving direction
Fig. 19 compares the efficiency performance between conventional single-phase system (one transmitter) and the proposed three-phase one. The DC-to-DC efficiency of the WDC system was measured by a YOKOGAWA WT1600 Power Analyzer. During both tests, receiver only moves along the driving direction from displacement $x$ of $60 \mathrm{~cm}$ to $120 \mathrm{~cm}$ (be equivalent to $l_{o} / 2$ ) with the reference point at the beginning of transmitter. Resistive load is adjusted so that output powers are 1 and $3 \mathrm{~kW}$ for single and three-phase system, respectively. The results indicate that efficiency drops significantly to nearly zero in the single-phase system at the points of 60 and $120 \mathrm{~cm}$ (i.e. null-mutual-inductance points). Efficiency then increases when receiver moves either from 70 to $90 \mathrm{~cm}$ or in reverse direction from 110 to $90 \mathrm{~cm}$ and reaches to maximum of $89.6 \%$ at $90 \mathrm{~cm}$. Differentiating from single-phase system, the proposed three-phase offers a nearly constant efficiency along the driving direction as output power are kept unchanged when receiver moving. At the rated power of $3 \mathrm{~kW}$ then efficiency achieve around $87.8 \%$.

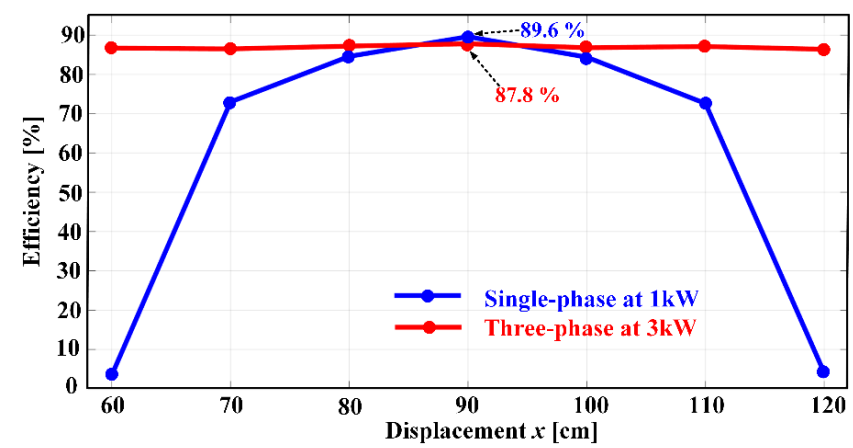

Fig. 19. Efficiency comparison between single-phase and three-phase system

The performance of proposed WDC is further investigated under lateral misalignment with different air-gap, $h$ of 5,10 and $15 \mathrm{~cm}$. As demonstrated in Fig. 20(a), the output power reduces with higher lateral misalignment between the receiver and the transmitter. The output power also drops as the air-gap between the receiver and transmitter increases. Under testing conditions of $15 \mathrm{~cm}$ air-gap and $30-\mathrm{cm}$ misalignment, then the output power reaches to $29 \%$ of the maximum power of $3 \mathrm{~kW}$. Furthermore, Fig. 20(b), illustrates the system efficiency across a wide range of misalignment as well as for different air gaps. As expected, higher efficiency attained with smaller misalignment as can be seen from the same figure.

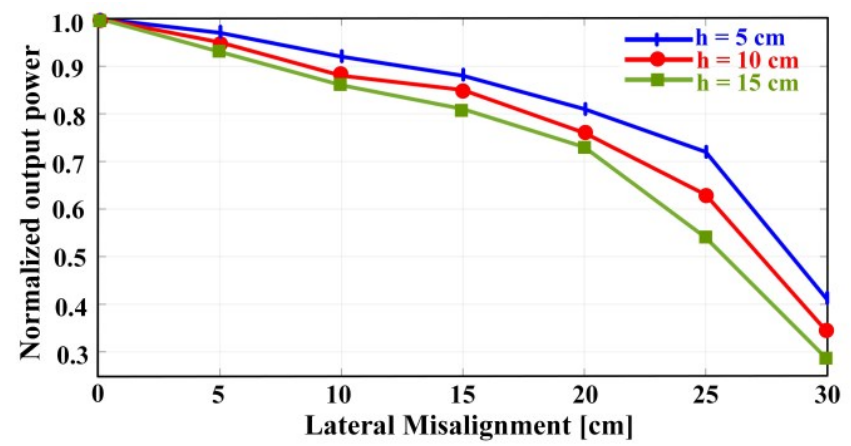

(a) 


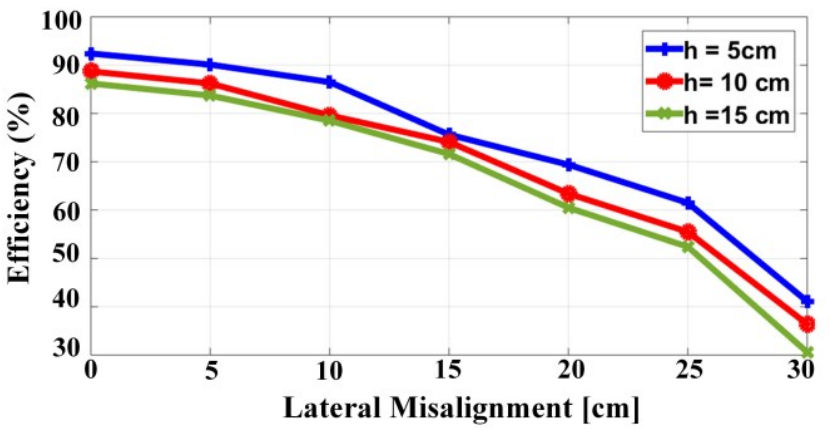

(b)

Fig. 20 System performance under different lateral misalignments and airgap value at rated power $\left(R_{o}=70 \Omega\right.$ ) (a) Normalized output power, (b) Measured output efficiency.

To realize the effect of the crossing couplings between the multiple windings on Inverter's switches and resonant components, we conducted two different tests with and without compensated capacitors $C_{\text {com } 1}, C_{c o m 2}$ and $C_{c o m 3}$. In both tests, the temperature of the semiconductor devices of the primary inverter is measured using FLIR E5 thermal imaging camera. As it can be observed from Fig. 21, before adding the compensating capacitors, the temperature on the power MOSFET reaches $123^{\circ} \mathrm{C}$ with only $0.2 \mathrm{~kW}$ output power and $300 \mathrm{~V}$ input DC. However, once the compensating capacitors are added, the temperature does not exceeds $105^{\circ} \mathrm{C}$ at full load (i.e. $3 \mathrm{~kW}$ ). Hence, the crossings mutual inductances in multiphase system must be carefully compensated in order to attain the maximum power transfer without exceeding the thermal limits.

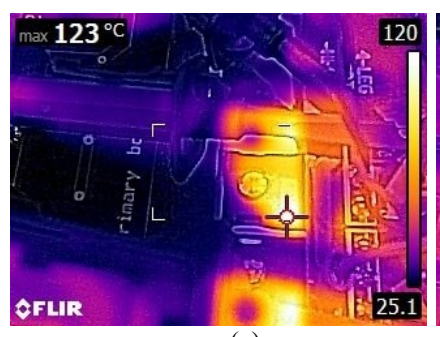

(a)

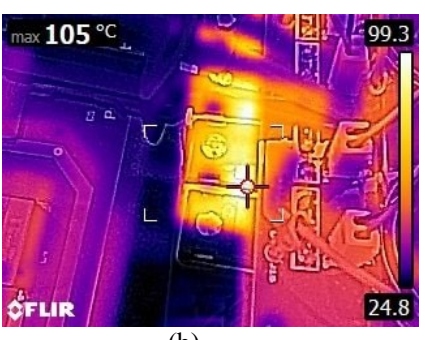

(b)
Fig. 21 Temperature comparison of MOSFET inverter under different tes conditions (a) without compensated capacitors when $P_{o}=\mathbf{2 0 0} \mathbf{W}$, (b) with compensated capacitors when $P_{o}=\mathbf{2 9 6 0} \mathrm{W}$.

For completeness, the effect of the crossing mutual inductances on the primary side components is also investigated. Table III summarises the current stress on the inverter switches $\left(S_{1}, S_{2}, S_{3}, S_{4}, S_{5}, S_{6}\right)$, the additional inductors $\left(L_{1 a}, L_{2 a}, L_{3 a}\right)$ and the parallel capacitors $\left(C_{1 a}, C_{2 a}\right.$, $C_{3 a}$ ), with and without compensating capacitors. It should be noted that, the current through the series capacitors and the transmitters will not be effected by the crossing mutual inductances. The temperature of power MOSFETs can be very high without compensating capacitors, therefore only simulation results are provided in this case. The parameters of mutual inductances $M_{1 s}, M_{2 s}$ and $M_{3 s}$ in simulation are adjusted to match with their experimental parameters, (i.e. $M_{1 s}=-6.18 \mu \mathrm{H}, M_{2 s}=12.5 \mu \mathrm{H}, M_{3 s}=-6.27 \mu \mathrm{H}$ ). Load resistances in both cases are set as $45 \Omega$. The difference of current stresses is clearly depicted in TABLE III between two cases. RMS currents on switches and components go up to very high value when compensated capacitors are not included. Oppositely, component's currents reduce significantly once including compensated capacitors which helps to suppress crossing induced voltages on each transmitter.
TABLE III

COMPARISON OF RMS CURRENT STRESSES ON PRIMARY COMPONENTS

\begin{tabular}{|c|c|c|}
\hline Components & $\begin{array}{l}\text { Excluding compensated } \\
\text { capacitors } \\
\text { (simulation results) [A] }\end{array}$ & $\begin{array}{l}\text { Including compensated } \\
\text { capacitors } \\
\text { (experimental results) }[\mathrm{A}]\end{array}$ \\
\hline$S_{l}$ & 24.3 & 1.78 \\
\hline$S_{2}$ & 24.4 & 7.13 \\
\hline$S_{3}$ & 29.3 & 6.98 \\
\hline$S_{4}$ & 24.3 & 1.78 \\
\hline$S_{5}$ & 24.4 & 7.13 \\
\hline$S_{6}$ & 29.3 & 6.98 \\
\hline$L_{l a}$ & 22.6 & 3.23 \\
\hline$L_{2 a}$ & 22.7 & 6.46 \\
\hline$L_{3 a}$ & 18.4 & 3.56 \\
\hline$C_{l a}$ & 38.4 & 18.75 \\
\hline$C_{2 a}$ & 38.2 & 18.87 \\
\hline$C_{3 a}$ & 27.3 & 14.45 \\
\hline
\end{tabular}

Finally, Electromagnetic Irradiation (EMI) surrounding the transmitter coils are measured under different distances far away from the coil's centre $d_{l}$ and different displacement $x$ along the driving direction as shown in Fig. 22. The Gauss Meter SPECTRAN NF-5030 is used as the measurement sensor. According to ICNIRP exposure limits, then the measured flux density is below $27 \mu \mathrm{T}$ at the positions of 0.8 meters far away from the transmitter.

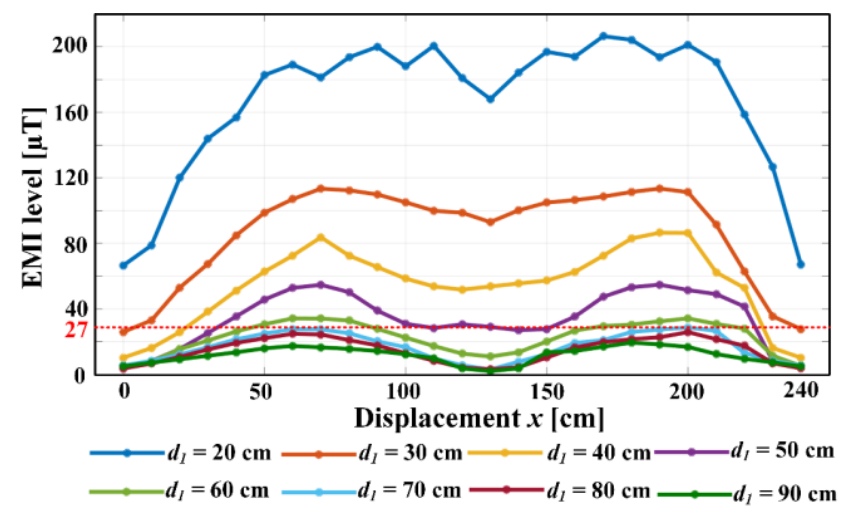

Fig. 22. Magnetic field measurement at different horizontal conditions

\section{SYSTEM COMPARISON}

In order to demonstrate the benefits of the proposed multiphase WDC system, a comparison with other similar WDC systems [12, 13, 14, 21, 22] that have the advantage of low EMI and narrow transmitter's width is carried out. The first feature to consider is of output power capability. For the sake of a sensible comparison, the following assumptions are considered: 1) output power is normalized by having the same transmitter current, coupling factor, switching frequency and load resistance for each system. 2) the same compensation 
circuit at the secondary side of each system. Please note that output power in [14], [21] depends on the number of receiver's windings (phases). The case of two parallel receiver phases is reported here. As it can be seen from Table $\mathrm{IV}$, the proposed WDC system offers a constant and high output power (i.e. 2.25 times higher as compared to other systems). This is a clear advantage when high power demand is required.

Other comparisons can be found from Table IV. Apart from [22], other systems are incapable of producing constant power, however two inverters are required in [22] as opposed to only one inverter in the proposed WDC. Although the output power is different from system to another, however the proposed system achieves higher efficiency, when tested at a full load. This apparently because the system is optimized to achieve the highest magnetic coupling and also the utilization of the state of the art of SiC MOSFETs, which have the low on-state resistance.
Interestingly, the control of the secondary side is independent from the primary one, which is not the case with other reported systems. This makes the proposed system more attractive when multiple vehicle charging is needed. However, in the case of other systems, mutual inductances and load resistances information are essential, which makes infeasible with multiple EVs in motion.

On the other hand, transmitter's copper lengths between different systems are calculated and compared for one kilometre of dynamic charging road. It should be noted that the proposed system requires more copper wire at the transmitter side. However, this can be justified with the extra benefits that are gained. Nevertheless, different winding arrangement can be considered to reduce the required copper length as discussed in Section II. C. Finally, the comparison is summarised in Table IV.

TABLE IV

COMPARISON OF VARIOUS DWC SYSTEMS

\begin{tabular}{|c|c|c|c|c|c|}
\hline & Ref. [12] & Ref. [13] & Ref. [22] & Ref. [14], [21] & The proposed one \\
\hline $\begin{array}{l}\text { Tested Output } \\
\text { Power }\end{array}$ & $35 \mathrm{~kW}$ & $22 \mathrm{~kW}$ & $250 \mathrm{~W}$ (Scale down) & $10 \mathrm{~kW}$ & $\begin{array}{c}3 \mathrm{~kW} \text { (can be } \\
\text { increasable) }\end{array}$ \\
\hline $\begin{array}{c}\text { Operating } \\
\text { frequency } \\
(\mathrm{kHz})\end{array}$ & 20 & 20 & 20 & 20 & 85 \\
\hline $\begin{array}{c}\text { Maximum } \\
\text { Efficiency (\%) }\end{array}$ & 74 & 71 & - & - & 87.6 \\
\hline $\begin{array}{c}\text { Normalized } \\
\text { output power } \\
\text { versus the driving } \\
\text { direction }\end{array}$ & $V_{0} V$ & $V_{0} V_{\text {Displacement } x}$ & 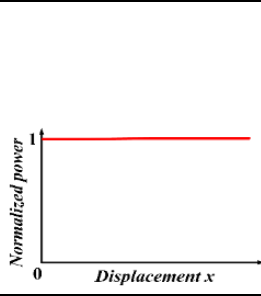 & ¿ & 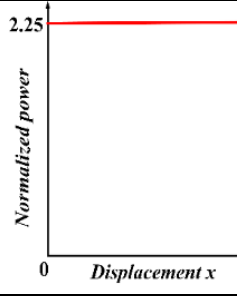 \\
\hline $\begin{array}{c}\text { Output power } \\
\text { variation along } \\
\text { driving direction }\end{array}$ & Not stable & Not stable & Stable & Not Stable & Stable \\
\hline $\begin{array}{c}\text { Number of } \\
\text { Primary Inverter }\end{array}$ & $\begin{array}{c}1 \\
\text { (Single phase full- } \\
\text { bridge) }\end{array}$ & $\begin{array}{c}1 \\
\text { (Single phase full- } \\
\text { bridge) }\end{array}$ & $\begin{array}{c}2 \\
\text { (Single phase full- } \\
\text { bridge) }\end{array}$ & - & $\begin{array}{c}1 \\
\text { (conventional three } \\
\text { phase) }\end{array}$ \\
\hline $\begin{array}{l}\text { Transmitter's } \\
\text { width }(\mathrm{cm})\end{array}$ & $\begin{array}{c}10 \\
\text { (I type core shape) }\end{array}$ & $\begin{array}{c}4 \\
\text { (S type core shape) }\end{array}$ & $\begin{array}{c}10 \\
(d q \text { I-type core shape) }\end{array}$ & $\begin{array}{c}10 \\
\text { (N type core shape) }\end{array}$ & $\begin{array}{c}12 \\
\text { (Multiphase I-type } \\
\text { core) }\end{array}$ \\
\hline $\begin{array}{l}\text { Transmitter's } \\
\text { copper length }\end{array}$ & $\begin{array}{c}8000 \\
(1 \text { transmitter's } \\
\text { winding) } \\
\end{array}$ & $\begin{array}{c}6000 \\
(1 \text { transmitter's } \\
\text { winding) }\end{array}$ & $\begin{array}{c}16000 \\
(2 \text { transmitter's } \\
\text { winding) }\end{array}$ & $\begin{array}{c}12000 \\
\text { (1 transmitter's } \\
\text { winding) }\end{array}$ & $\begin{array}{c}20400 \\
\text { (3 transmitter's } \\
\text { winding) } \\
\end{array}$ \\
\hline $\begin{array}{l}\text { Receiver's } \\
\text { dimension }\end{array}$ & $\begin{array}{l}80 \mathrm{~cm} \times 100 \mathrm{~cm} \\
\text { (1 winding) }\end{array}$ & $\begin{array}{l}80 \mathrm{~cm} \times 100 \mathrm{~cm} \\
\text { (1 winding) }\end{array}$ & $\begin{array}{l}90 \mathrm{~cm} \times 100 \mathrm{~cm} \\
\text { (1 winding) }\end{array}$ & $\begin{array}{c}90 \mathrm{~cm} \times 108 \mathrm{~cm} \\
(2 \text { windings in } \\
\text { parallel*) }\end{array}$ & $\begin{array}{c}60 \mathrm{~cm} \times 60 \mathrm{~cm} \\
\text { (1 winding) }\end{array}$ \\
\hline Air gap $(\mathrm{cm})$ & 20 & 20 & 15 & 20 & 15 \\
\hline $\begin{array}{l}\text { Possibility of } \\
\text { multiple vehicle } \\
\text { charging }\end{array}$ & No & No & No & - & Yes \\
\hline $\begin{array}{l}\text { Load-dependent } \\
\text { measurement }\end{array}$ & Yes & Yes & Yes & Yes & No \\
\hline
\end{tabular}

Note:- means no information available from the reference. 


\section{CONCLUSION}

This paper presented a constant and high output power WDC for EVs, utilizing multi-winding with alternative ferrite poles in primary side to effectively produce a constant coupling magnetic flux between transmitters and receiver. The detailed layout for transmitter along with the conditions of transmitter current are analysed and discussed in the paper. An illustrative three-phase example of WDC demonstrated the feasibility of the proposed system. The effect of crossing mutual inductance is thoroughly analysed and a re-design of the series capacitors in LCC compensation tank is presented to overcome this effect. The paper also presented the magnetic design of the transmitter and the receiver that attain large coupling coefficient, and minimum loss of power under lateral misalignment with less ferrite core and copper cable.

The feasibility of the proposed system is experimentally validated using a $3 \mathrm{~kW}$ laboratory prototype, tested under different operating conditions. The power fluctuation factor at rated load can attain 5.6\% while maximum efficiency reaches $87.8 \%$. A detailed comparison with other similar works is conducted and the main advantages can be pointed out such as (1) achieving a constant and higher output power, (2) using less number of Inverters, (3) elimination of measurement load and (or) coupling from secondary side, (4) supporting the multiple EV charging without any complex control.

\section{REFERENCES}

[1] M. Yilmaz and P. T. Krein, "Review of battery charger topologies, charging power levels, and infrastructure for plugin electric and hybrid vehicles," IEEE Trans. Power Electron., vol. 28, no. 5, pp. 2151-2169, May 2013.

[2] S. Y. Choi , B. W. Gu , S. Y. Jeong, C. T. Rim "Advances in Wireless Power Transfer Systems for Roadway-Powered Electric Vehicles," IEEE J. Emerg. Sel. Topics Power Electron., vol. 3, no. 1, pp. 18-36, Mar. 2015.

[3] D. H. Tran, V. B. Vu and W. J. Choi, "Design of a High Efficiency Wireless Power Transfer System with Intermediate Coils for the On-board Chargers of Electric Vehicles," IEEE Trans. Power Electron., vol. 33, no. 1, pp. 175-187, Jan. 2018.

[4] V. B. Vu, D. H. Tran and W. J. Choi, "Implementation of the Constant Current and Constant Voltage Charge of Inductive Power Transfer Systems with the Double-Sided LCC Compensation Topology for Electric Vehicle Battery Charge Applications," IEEE Trans. Power Electron., vol. 33, no. 9, pp. 7398 - 7410,Sep. 2018.

[5] V. B. Vu, V. T. Phan, M. Dahidah and V. Pickert, "Multiple Output Inductive Charger for Electric Vehicles," IEEE Trans. Power Electron., vol. 34, no. 8, pp. 7350-7368, Aug. 2018.

[6] G. A. Covic and J. T. Boys, "Modern trends in inductive power transfer for transportation applications," IEEE J. Emerg. Sel. Topics Power Electron., vol. 1, no. 1, pp. 28-41, Mar. 2013.

[7] Q. Zhu, L. Wang, Y. Guo, C. Liao, and F. Li, "Applying LCC compensation network to dynamic wireless EV charging system," IEEE Trans. Ind. Electron., vol. 63, no. 10, pp. 65576567, Oct. 2016.

[8] J. M. Miller, O. C. Onar, C. P. White, and S. Campbell, "Demonstrating dynamic wireless charging of an electric vehicle: The benefit of electrochemical capacitor smoothing," IEEE Power Electron. Mag., vol. 1, no. 1, pp. 12-24, Mar. 2014

[9] J. Shin et al., "Design and implementation of shaped magnetic resonance based wireless power transfer system for roadwaypowered moving electric vehicles," IEEE Trans. Ind. Electron., vol. 61, no. 3, pp. 1179-1192, Mar. 2014.
[10] B.-M. Song, R. Kratz, and S. Gurol, "Contactless inductive power pickup system for Maglev applications," in Proc. 37th IEEE IAS Annu. Meeting, Oct. 13-18, 2002, vol. 3, pp. 15861591.

[11] W. Y. Lee et al., "Finite-width magnetic mirror models of mono and dual coils for wireless electric vehicles," IEEE Trans. Power Electron., vol. 28, no. 3, pp. 1413-1428, Mar. 2013.

[12] J. Huh, S. W. Lee, W. Y. Lee, G. H. Cho, and C. T. Rim, "Narrow-width inductive power transfer system for on-line electrical vehicles (OLEV)," IEEE Trans. Power Electron., vol. 26, no. 12, pp. 3666-3679, Dec. 2011.

[13] S. Y. Choi, S. Y. Jeong, B. W. Gu, G. C. Lim, and C. T. Rim, "Ultraslim S-type power supply rails for roadway-powered electric vehicles," IEEE Trans. Power Electron., vol. 30, no. 11, pp. 6456-6468, Nov. 2015.

[14] Zhiyuan Wang, Shumei Cui, Shouliang Han, Kai Song, Chunbo Zhu, Milyaev Igor Matveevich, Ostanin Sergei Yurievich, "A Novel Magnetic Coupling Mechanism for Dynamic Wireless Charging System for Electric Vehicles", IEEE Trans. Veh. Technol., vol. 67, no. 1, pp. 124-133, 2018.

[15] J. Zhao, T. Cai, S. Duan, H. Feng, C. Chen, and X. Zhang, "A General Design Method of Primary Compensation Network for Dynamic WPT System Maintaining Stable Transmission Power," IEEE Trans. Power Electron., vol. 31, no. 12, pp. 8343-8358, Dec. 2016.

[16] H. Feng, T. Cai, S. Duan, J. Zhao, X. Zhang, and C. Chen, “An LCC-compensated resonant converter optimized for robust reaction to large coupling variation in dynamic wireless power transfer," IEEE Trans. Ind. Electron., vol. 63, no. 10, pp. 65916601, Oct. 2016.

[17] F. Lu, H. Zhang, H. Hofmann, and C. C. Mi, "A dynamic charging system with reduced output power pulsation for electric vehicles," IEEE Trans. Ind. Electron., vol. 63, no. 10, pp. 6580-6590, Oct. 2016.

[18] H. Li, Y. Liu, K. Zhou, Z. He, W. Li, R. Mai, "Uniform Power IPT System With Three-Phase Transmitter and Bipolar Receiver for Dynamic Charging," IEEE Trans. Power Electron., vol. 34, no. 3, pp. 2013-2017, 2019.

[19] C.-Y. Huang, J. E. James, and G. A. Covic, "Design considerations for variable coupling lumped coil systems," IEEE Trans. Power Electron., vol. 30, no. 2, pp. 680-689, Feb. 2015.

[20] M. Kim, D.-M. Joo, and B. K. Lee, "Design and control of inductively power transfer system for electric vehicles considering wide variation of output voltage and coupling coefficient," IEEE Trans. Power Electron., vol. 34, no. 2, pp. 1197-1208, Feb. 2019.

[21] S. Cui, Z. Wang, S. Han, C. Zhu and C. C. Chan, "Analysis and Design of Multiphase Receiver with Reduction of Output Fluctuation for EV Dynamic Wireless Charging System," IEEE Trans. Power Electron., vol. 34, no. 5, pp. 4112-4124, May. 2019.

[22] C. Park, S. Lee, S. Jeong, G.-H. Cho, and C. Rim, "Uniform power I-type inductive power transfer system with DQ-power supply rails for on-line electric vehicles," IEEE Trans. Power Electron., vol. 30, no. 11, pp. 6446-6455, Nov. 2015.

[23] J. Kim, B. Lee, J. Lee, S. Lee, C. Park, S. Jung, S. Lee, K. Yi, and J. Baek, "Development of 1MW Inductive Power Transfer System for a High Speed Train," IEEE Trans. Ind. Electron., vol. 62, no. 10, pp. 6242-6250, Oct. 2015.

[24] Y. Li, R. Mai, L. Lu, and Z. He, "Active and reactive currents decomposition based control of angle and magnitude of current for a parallel multi-inverter IPT system," IEEE Trans. Power Electron., vol. 32, no. 2, pp. 1602-1614, Feb. 2017.

[25] Y. Li, R. Mai, L. Lu, T. Lin, Y. Liu and Z. He, "Analysis and Transmitter Currents Decomposition Based Control for Multiple Overlapped Transmitters Based WPT Systems Considering Cross Couplings," IEEE Trans. Power Electron. vol. 33 , no. 2 , pp. 1829 - 1842, Feb. 2018.

[26] SAE International, "Wireless power transfer for light-duty plugin/electric vehicles and alignment methodology," 2017. 
[27] S. Li, W. Li, J. Deng, T. D. Nguyen, and C. C. Mi, "A doublesided LCC compensation network and its tuning method for wireless power transfer," IEEE Trans. Veh. Technol., vol. 64, no. 6, pp. 2261-2273, Jun. 2015.

[28] M. L. G. Kissin, J. T. Boys, and G. A. Covic, "Interphase mutual inductance in poly-phase inductive power transfer systems," IEEE Trans. Ind. Electron., vol. 56, no. 7, pp. 2393 2400, Jul. 2009.

[29] [Online] Characteristics of Mn-Zn ferrite materials - TDK Product Center. Available: https://product.tdk.com

[30] M. Misakian, "Equations for the magnetic field produced by one or more rectangular loops of wire in the same plane," Journal of Research-National Institute of Standards And Technology, vol. 105, no. 4, July. 2000.

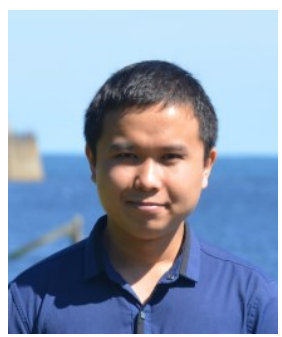

Van-Binh Vu (S'17) received the Bachelor degree (talented program) from Hanoi University of Science and Technology, Hanoi, Vietnam, in 2014, and the Master degree from Soongsil University, Seoul, Republic of Korea in 2016, both in Electrical Engineering. He is currently working toward the Ph.D. degree in power electronics with the School of Engineering, Newcastle University, Newcastle upon Tyne, U.K. His main research areas include the fields of Power Electronics, especially on Wireless Power Transfer for Electric Vehicles.

He has authored or co-authored of 4 papers published in the top-tier IEEE journals and has filled 1 patent on wireless power transfer technologies. He has served as a reviewer for the IEEE Transactions on Industrial Electronics, the IEEE Transactions on Power Electronics and the IEEE Journal of Emerging and Selected Topics in Power Electronics.

$\mathrm{Mr}$. Vu has been awarded a travel grant from IEEE Industrial Electronics Society to attend the 26th IEEE International Symposium on Industrial Electronics.

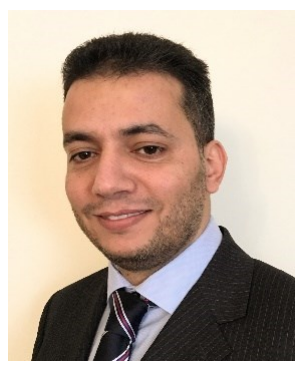

Mohamed Dahidah (M'02-SM'10) received the $\mathrm{Ph} . \mathrm{D}$. degree in electrical engineering from Multimedia University, Malaysia, in 2008.

Dr Dahidah was an Assistant Professor in the Department of Electrical and Electronic Engineering, The University of Nottingham, Malaysia Campus, till November 2012. He is currently a Senior Lecturer with the School of Engineering, Newcastle University, Newcastle Upon Tyne, U.K. He has authored or co-authored a number of refereed journal and conference papers.

His research interests include modular multilevel converters, SHE-PWM modulation technique for power electronics converters, battery charger for EVs, solid state transformers and renewable energy integration.

Dr. Dahidah is the Deputy Editor-in-Chief for IET Power Electronics and has been a regular reviewer for both IEEE and IET journals.

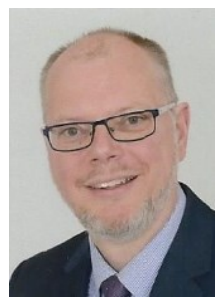

Volker Pickert (M'04) studied at the RWTH Aachen, Germany, and Cambridge University, UK, and he received his Dipl.-Ing. degree in Electrical and Electronic Engineering from RWTH Aachen in 1994. He was awarded the $\mathrm{Ph} . \mathrm{D}$. degree in power electronics from Newcastle University, Newcastle upon Tyne, U.K., in 1997.

From 1998 to 1999, he was an Application Engineer with Semikron GmbH, Nuremberg, Germany, and from 1999 to 2003 he was a Group Leader at Volkswagen AG, Wolfsburg, Germany, responsible for the development of electric drives for electric vehicles. In 2003, he was appointed as a Senio Lecturer in the Electrical Power Group, Newcastle University, and in 2011 he became a Full Professor of Power Electronics. In 2012, he became the Head of the Electrical Power Group. He has published more than 150 book chapters, journal, and conference papers in the area of power electronics and electric drives. His current research interests include power electronics for transport applications, thermal management, health monitoring techniques, and advanced nonlinear control.

Prof. Pickert received the IMarEST Denny Medal for the best article in the Journal of Marine Engineering in 2011 and in 2018 he received the Best Paper Award at IEEE International Conference on Computing Electronics \& Communications Engineering (iCCECE), Essex, UK. He is regularly invited as keynote speaker and advises various governments on energy and transport related issues. In 2019 he also became the Director of UK's EPSRC Doctoral Training Centre in Power Electronics for Sustainable Electric Propulsion. He is the active Editor-in-Chief of the IET Power Electronics journal.

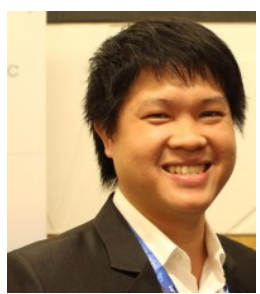

Van-Tung Phan (GS'07-M'11-SM'13) received the bachelor's degree in electrical and electronic engineering from the Ho Chi Minh City University of Technology, Ho Chi Minh City, Vietnam, and the Ph.D. degree in electrical engineering from the University of Ulsan, Ulsan, South Korea. He was a Research Fellow with the Energy Research Institute@NTU, Nanyang Technological University (NTU) Singapore.

He is currently a Lecturer of electrical power engineering with Newcastle University (Singapore Campus), Singapore. He has authored or co-authored several internationally referred journal papers, book chapters, and conference papers on power electronics. His current research interests include on wireless power transfer system for electric vehicles, dual active bridge dc$\mathrm{dc}$ converters, bi-directional ac-dc converters, $\mathrm{dc}-\mathrm{ac}$ inverters, and $\mathrm{dc}-\mathrm{dc}$ converters in electrified vehicles and renewable energy applications, such as solar and wind, on-board and off-board chargers, dc fast chargers for electric vehicles; vehicle-to-grid interface technologies and grid-tied photovoltaic micro-inverters and solar-powered electric vehicles charging stations.

Dr. Phan was a recipient of the 2013 IET Electric Power Applications Premium Award. He is a Senior Member of the IEEE Industrial Electronics Society, IEEE Power Electronics Society, IEEE Vehicular Technology Society, and IEEE Industry Applications Society. 